\title{
"MATH+" Multi-Modal Hospital Treatment Protocol for COVID-19 Infection: Clinical and Scientific Rationale
}

\author{
Pierre Korya, f, Ginfranco Umberto Meduri ${ }^{\mathrm{b}}$, Jose Iglesias ${ }^{\mathrm{c}}$, Joseph Varon ${ }^{\mathrm{d}}$, \\ Flavio Adsuara Cadegiani ${ }^{\mathrm{e}}$, Paul E. Marik ${ }^{\mathrm{a}}$
}

\begin{abstract}
In December 2019, coronavirus disease 2019 (COVID-19), a severe respiratory illness caused by the new coronavirus severe acute respiratory syndrome coronavirus 2 (SARS-CoV-2) emerged in Wuhan, China. The greatest impact that COVID-19 had was on intensive care units (ICUs), given that approximately $20 \%$ of hospitalized cases developed acute respiratory failure (ARF) requiring ICU admission. Based on the assumption that COVID-19 represented a viral pneumonia and no anti-coronaviral therapy existed, nearly all national and international health care societies recommended "supportive care only" avoiding other therapies outside of randomized controlled trials, with a specific prohibition against the use of corticosteroids in treatment. However, early studies of COVID-19-associated ARF reported inexplicably high mortality rates, with frequent prolonged durations of mechanical ventilation (MV), even from centers expert in such supportive care strategies. These reports led the authors to form a clinical expert panel called the Front-Line COVID-19 Critical Care Alliance (www.flccc.net). The panel collaboratively reviewed the emerging clinical, radiographic, and pathological reports of COVID-19 while initiating multiple discussions among a wide clinical network of front-line clinical ICU experts from initial outbreak areas in China, Italy, and New York. Based on the shared early impressions of "what was working and what wasn't working", the increasing medical journal publications and the rapidly accumulating personal clinical experiences with COVID-19 patients, a treatment protocol was created for the hospitalized patients based on the core therapies of methylprednisolone, ascorbic acid, thiamine, heparin and non-antiviral co-interventions (MATH+). This manuscript reviews the scientific and clinical rationale behind MATH+ based on published in-vitro, pre-clinical, and clinical data in support of each medicine, with a special emphasis of studies supporting their use in the treatment of patients with viral syndromes and COVID-19 specifically.
\end{abstract}

Manuscript submitted January 5, 2022, accepted February 8, 2022

Published online February 24, 2022

${ }^{a}$ Front Line Critical Care Consortium (FLCCC.org), Washington DC, USA ${ }^{b}$ Department of Medicine, University of Tennessee Health Science Center, Memphis, TN, USA

cJersey Shore University Medical Center, Hackensack School of Medicine at Seton Hall, NJ, USA

${ }^{\mathrm{d}}$ University of Texas Health Science Center, Houston, TX, USA

${ }^{e}$ Corpometria Institute, Brasilia, Brazil

${ }^{f}$ Corresponding Author: Pierre Kory, Front Line Critical Care Consortium (FLCCC.org), Washington DC, USA. Email: pierrekory@icloud.com

doi: https://doi.org/10.14740/jocmr4658
Keywords: MATH plus; Methylprednisolone; Ascorbic acid; Thiamine; Heparin

\section{Introduction}

In December 2019, coronavirus disease 2019 (COVID-19), an illness characterized by pneumonia associated with the new coronavirus severe acute respiratory syndrome coronavirus 2 (SARS-CoV-2) emerged in Wuhan, China. By March 11, 2020, the World Health Organization (WHO) had characterized the novel coronavirus outbreak as a pandemic, with confirmed cases in 213 countries. The greatest impact this malady had was on intensive care units (ICUs), given approximately $20 \%$ of hospitalized cases developed acute respiratory failure (ARF) requiring ICU admission $[1,2]$.

Since COVID-19 was initially defined as a primary viral syndrome and no validated anti-coronavirus therapy existed, nearly all national and international health care societies advocated a primary focus on supportive care with avoidance of other therapies outside of randomized controlled trials (RCTs), and with specific recommendations to avoid the use of corticosteroids [3-5].

The pervasive belief amongst world health care societies that corticosteroids were harmful in COVID-19 respiratory illness was surprising for several reasons. First, as will be detailed in this manuscript, contrary to the WHO and CDC's interpretation of prior pandemic data, a review of the same data by a group including one of the authors (GUM) was both published and publicized by the Society for Critical Care Medicine in early April 2020 which concluded that the largest and most well-controlled studies from the severe acute respiratory syndrome (SARS), Middle East respiratory syndrome (MERS), and H1N1 pandemics found that the mortality of patients with moderate to severe illness was significantly reduced when treated with corticosteroids [6]. Second, reports from the "front-line" clinicians in Italy and New York reported on rapidly observable, positive impacts when corticosteroids were used in treatment. Further, an expert panel of US radiologists had published an tragically little-noticed review of the early computed tomography (CT) scans from Wuhan, China in March of 2020, where they concluded that the "most common pattern of lung injury in COVID-19 is of an organizing pneumonia" (OP), a condition accurately identifiable by CT 
scan and whose first-line therapy is corticosteroids. The presence of OP likely explains both the seemingly baffling clinical presentation of early COVID-19 respiratory disease as well as the efficacy of corticosteroids as evidenced in a recent review by one of the authors (PK) [7, 8].

However, in that period prior to the now-widespread use of corticosteroids, multiple early studies of COVID-19-associated ARF reported inexplicably high mortality rates, with frequent prolonged durations of mechanical ventilation (MV), even from centers expert in such supportive care strategies [9]. These reports led many physicians, including the authors of this manuscript, to question the widely recommended supportive care-only approach, and to review the evidence behind therapies that could counteract the well-recognized syndrome of severe hypoxemia, hyper-inflammation, and hypercoagulability, with the rationale that interventions targeted at these pathophysiologies could decrease dependence on mechanical ventilators and mortality in COVID-19 patients, and thus, have an immediate significant global impact on this public health emergency $[9,10]$.

As a group of clinical researchers in critical care with over a 100-year collective front-line, bedside ICU experience in the treatment of severe infections and acute respiratory distress syndrome (ARDS), the authors formed a clinical expert panel which we called the Front-Line COVID-19 Critical Care Alliance (www.flccc.net). The panel collaboratively reviewed the emerging clinical, radiographic, and pathological reports of COVID-19 while initiating multiple discussions among a wide clinical network of front-line clinical ICU experts from initial outbreak areas in China, Italy, and New York. Based on the shared early impressions of "what was working and what wasn't working", the increasing medical journal publications and the rapidly accumulating personal clinical experiences with COVID-19 patients, a treatment protocol was created for hospitalized patients, adapted from a protocol created by one of the authors (PEM) at their home institution. The protocol consisted of the four "core" therapies of methylprednisolone, ascorbic acid (AA), thiamine, heparin, and a number of co-interventions and thus was called "MATH+" (Table 1). The core medicines were all highly familiar, low-cost, FDA-approved medications with known therapeutic mechanisms, well-established safety profiles and multiple clinical trials showing benefit in similar disease models such as ARDS. The additional co-interventions were also supported by either promising early clinical data, strong scientific rationale, and/or a pre-existing clinical evidence base for similar critical care conditions as those in COVID-19. Since the development of MATH+ early in the pandemic, the treatment efficacy of the majority of the protocol components (corticosteroids, AA, heparin, statins, vitamin $\mathrm{D}$, and melatonin) has now been either validated in subsequent RCTs or more strongly supported with large observational data sets [11-16].

Many centers similarly attempted to develop "treatment guidelines" for COVID-19, and although they primarily emphasized supportive respiratory care techniques, many also included approaches either quickly retracted as obviously harmful, such as "early intubation" or therapeutic agents and interventions whose mechanisms of action held only theoretical anti-SARS-CoV-2 activity [17-21].
The authors were troubled by editorials published in major peer-reviewed medical journals which argued that all treatments used in a "novel" disease were "experimental" and thus use should be restricted to only within RCTs [22]. "Experimental" therapies, best defined as those with either no clinical evidence to support or near nil clinical familiarity with use in similar disease states, were indeed adopted and widely used, particularly in the early weeks of the pandemic when drugs such as hydroxychloroquine, remdesivir, lopinavir/ritonavir and tocilizumab were employed. However, these agents stand in marked contrast to the core MATH+ therapies of which there was extensive clinical experience and expertise amongst the authors along with published clinical evidence showing positive outcomes when used in the treatment of patients with similar diseases and conditions. In some instances, several were already incorporated into standard ICU treatment protocols for conditions such as severe pneumonia, ARDS, and sepsis in their institutions. Each element of MATH+ has been extensively studied in critical illness, almost all sufficiently so that meta-analyses have been published on their use and indications, thus none could be viewed as an "experimental therapy", given they are considered more in line with "standard" or "supportive care" for many critical illness states.

Although the authors place immense value and importance on the need for well-conducted prospective observational and/ or RCTs, in such a novel disease syndrome, it must be recognized that not all institutions possess the necessary experience, resources, or infrastructure to design and conduct such trials, especially during a pandemic. Further, the group decided against a randomized, placebo-controlled trial design given that such trials require investigators to possess "clinical equipoise", which is the belief by the investigator that neither intervention in the control or experimental group is "better". With respect to each of the individual "core" therapies of MATH+, all authors felt the therapies either superior to any placebo or possessed evidence of minimal risk and cost compared to potential benefit such that use was favored, with these judgments based on not only the rapidly accumulated evidence and insight into COVID-19 but also from our collective knowledge, research, and experience with each of the component medications in critical illness and other severe infections.

Conversely, the authors believe it is within the immense power and resources of large research institutions to conduct such trials where clinical equipoise exists. A powerful example of such an accomplishment is the RECOVERY trial conducted by researchers at Oxford University [11]. Specifically, the design and execution of the RECOVERY trial depended on investigators with clinical equipoise around the use of corticosteroids in the treatment of a severe coronavirus syndrome. The $\mathrm{MATH}+$ authors did not possess such equipoise, as we held a collective belief as to the critical importance of corticosteroid therapy in COVID-19, as evidenced above [6, 8, 23].

Thus, it came as no surprise to the authors that the RECOVERY trial was stopped early due to excess deaths in a control group consisting of over 4,000 patients treated with placebo. A conservative estimate of avoidable death in the placebo group if they had instead received corticosteroids is that over 200 lives would have been saved, 109 in patients requiring oxygen and 84 in those on MV [11]. 


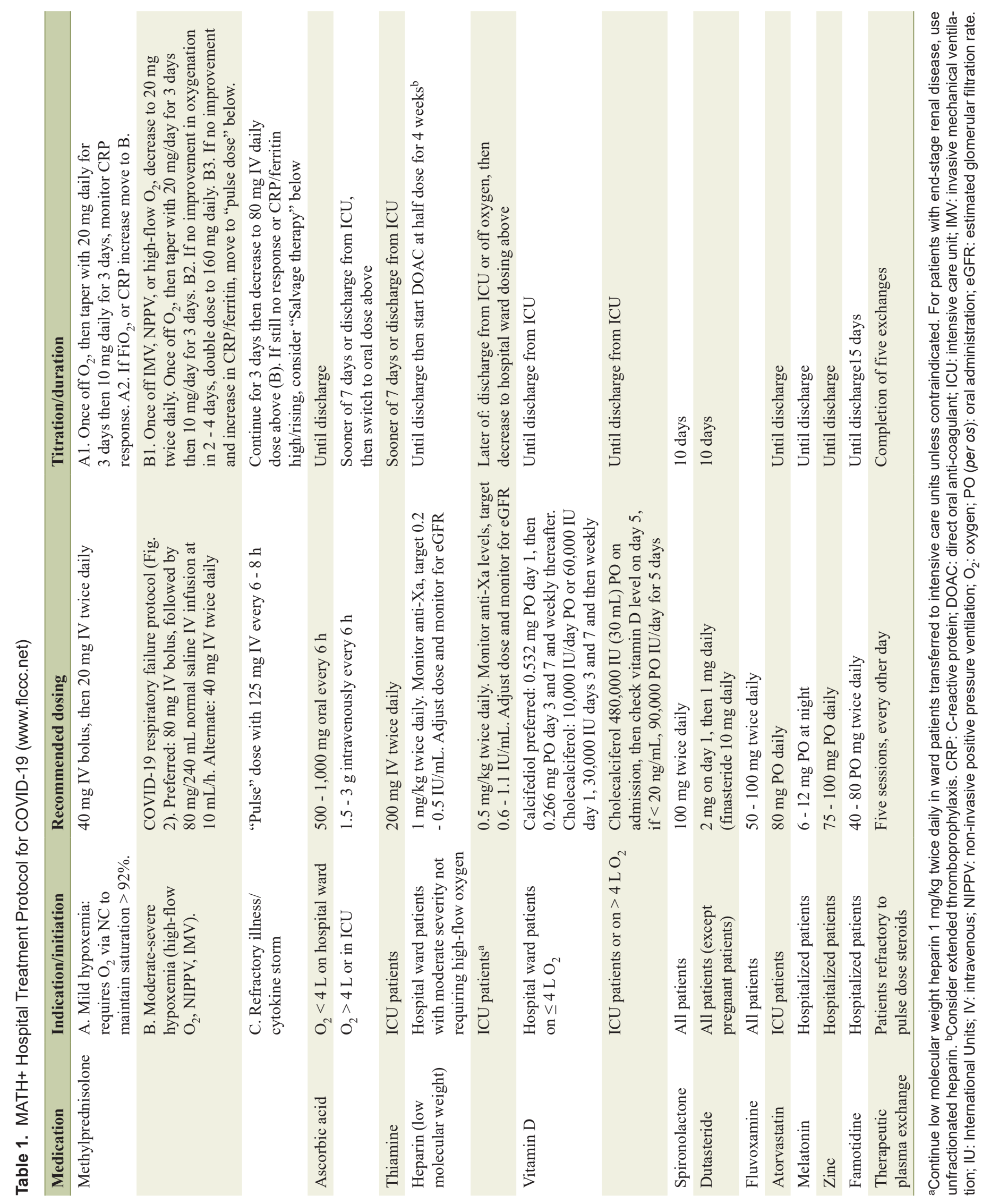


The scientific and clinical rationale supporting the MATH+ treatment protocol will be reviewed in the following sections through a review of the published in-vitro, pre-clinical, and clinical data in support of each medicine, with a special emphasis on studies involving the treatment of viral syndromes and COVID-19 specifically.

COVID-19 has several phases, a viremic asymptomatic and symptomatic phase of the disease which roughly occurs during the first 8 days of infection followed by pulmonary phases of the disease which in a small percentage of patient may lead to severe respiratory failure [24]. The major manifestations of the pulmonary phases of disease are not a result of direct viral effects, rather, it is hyper-inflammatory innate immune host response mainly driven by activated macrophages associated with thrombophilia and hypercytokinemia [24]. Thus, by the time that patients present with severe disease requiring hospitalization they generally are past the viremic phase and anti-viral therapy will most likely be ineffective. Therefore, the MATH plus protocol focuses on the management of the hyperinflammatory and coagulopathic manifestations of the disease.

\section{Methylprednisolone and COVID-19}

Methylprednisolone was chosen based on the following criteria: 1) evidence of corticosteroid responsive disease; 2) results of relevant clinical studies, many from prior viral pandemics including more than 10,000 patients; and 3) pharmacological characteristics.

Similar to ARDS, patients with severe COVID-19 have a significant reduction in glucocorticoid receptor expression in bronchoalveolar lavage fluid myeloid cells that negatively related to lung neutrophilic inflammation, NETosis, and disease severity $[25,26]$. The dysregulated inflammation and coagulation observed in COVID-19 (see pathophysiology) is also similar to that of multifactorial ARDS where ample evidence has demonstrated the ability of prolonged corticosteroid treatment (CST) to downregulate systemic and pulmonary inflammation-coagulation-fibroproliferation and accelerate disease resolution [25, 27]. Additionally, the CT findings of ground-glass opacities and the histological findings of organizing pneumonia, hyaline membranes, inflammatory exudates, and acute fibrinous and organizing pneumonia are all compatible with CST-responsive interstitial inflammatory lung disease [8, 28, 29].

Relevant clinical studies at the time of the creation of MATH+ included RCTs in adult patients with non-viral ARDS, large-scale observational studies in patients with SARS-CoV $(\mathrm{n}=7,008)$, H1N1 $(\mathrm{n}=2,141)$, influenza, and early results from multiple COVID-19 observational studies [30-36]. In non-viral ARDS, aggregate data from 10 RCTs $(n=1,093)$ showed that CST was associated with a sizable increase by day 28 in MV-free days (weighted mean difference (WMD): 6.18 days, 95\% confidence interval (CI): 3.45 - 8.90 days), ICUfree days (WMD: 8.12 days, 95\% CI: 3.87 - 12.37 days) and a reduction in hospital mortality (risk ratio (RR): $0.67,95 \% \mathrm{CI}$ : $0.52-0.870)$ with the greatest impact observed with methyl- prednisolone treatment $[6,33,37]$. Importantly, the survival benefit observed during hospitalization persisted after hospital discharge with follow-up observations extending up to 1 year [6]. Except for transient hyperglycemia (mostly within the $36 \mathrm{~h}$ following an initial bolus), CST was not associated with increased risk for neuromuscular weakness, gastrointestinal bleeding, or nosocomial infections (RR: 0.83 (95\% CI: $0.67-1.02))$.

The evidence of benefit in viral pneumonia (SARS and H1N1) relies on large-scale studies $(n=9,149)$ which included adjustment for confounders and analysis of CST variables (type, timing, dose, and duration) on the outcome [32, 33]. These studies reported a significant reduction in mortality with dosage and duration of CST similar to the one recommended by the Corticosteroid Guideline Task Force of the Society of Critical Care Medicine (SCCM) and the European Society of Intensive Care Medicine (ESICM) (Fig. 1) $[6,38]$. In the largest SARS-CoV study, after adjustment for possible confounders, methylprednisolone $80 \mathrm{mg} /$ day was safe and decreased the risk for death by $63 \%$ (hazard ratio (HR): $0.37,95 \% \mathrm{CI}$ : 0.24 - 0.56) [32]. In the H1N1 study, subgroup analysis among patients with $\mathrm{PaO}_{2} / \mathrm{FiO}_{2}<300 \mathrm{~mm} \mathrm{Hg}$ (535 vs. 462), lowto-moderate-dose CST (methylprednisolone 25 - $150 \mathrm{mg} /$ day) significantly reduced both 30-day mortality (adjusted hazard ratio (aHR): $0.49(95 \% \mathrm{CI}: 0.32-0.77))$ and 60 -day mortality (aHR: 0.51 (95\% CI: 0.33 - 0.78)) despite having a higher rate of nosocomial infections [33].

Methylprednisolone, for its greater penetration in lung tissue, longer residence time, and greater inhibitory activity of transcription factor nuclear factor- $\kappa \mathrm{B}(\mathrm{NF}-\kappa \mathrm{B})$ (driver of lung inflammation) is the most frequently used intravenous corticosteroid for the treatment of severe acute inflammatory lung diseases [39-41]. The initial daily dose of $1 \mathrm{mg} / \mathrm{kg}$ of ideal body weight (approximately $80 \mathrm{mg}$ ) was the one shown to be associated with the highest mortality reduction in RCTs of nonviral ARDS and large observational studies in SARS-CoV and H1N1 pneumonia $[6,32,33]$. A recent study that matched the expression changes induced by SARS-CoV-2 in human lung tissue tissues and A549 lung cell line against the expression changes triggered by 5,694 FDA-approved drugs, found methylprednisolone to be the drug with the greatest potential to revert the changes induced by COVID-19, while other closely related corticosteroids, such as dexamethasone or prednisone, were not [42].

The risk for decreased viral clearance with CST is overstated and the most frequently quoted article by Arabi et al reported that in patients that received greater than 7 days CST, there was a strong trend toward lower 90-day mortality (aOR: $0.51,95 \% \mathrm{CI}: 0.26-1.00 ; \mathrm{P}=0.05)$ and no impact on viral clearance (aOR: 0.94, 95\% CI: $0.36-2.47$; $\mathrm{P}=0.90$ ) [43]. Contrary to the widespread, unfounded fears of delayed viral clearance which unfortunately influenced the multiple national and international society recommendations against use of CST in COVID-19, the reality is that there is no evidence linking delayed viral clearance to worsened outcomes in critically ill COVID-19 patients, and further, it is unlikely that it would have a greater negative impact than the hosts own "cytokine storm" [27].

Subsequent to the introduction of the MATH+ protocol, 


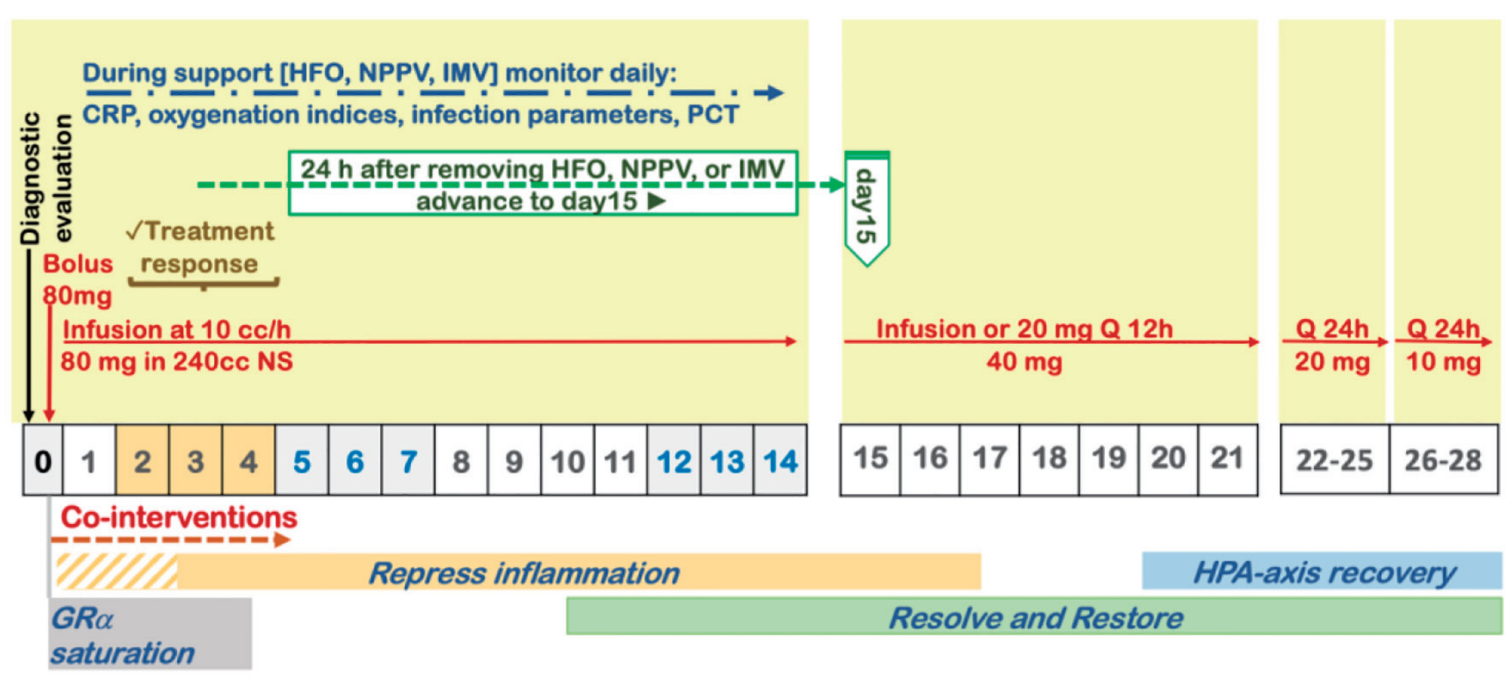

Figure 1. Protocol for prolonged corticosteroid treatment recommended by the Corticosteroid Guideline Task Force of the Society of Critical Care Medicine (SCCM) and the European Society of Intensive Care Medicine (ESICM).

even more definitive support for CST was provided by a large randomized trial along with prospective observational studies. The RECOVERY trial investigated dexamethasone (6 mg once daily for up to 10 days) in a randomized, controlled, open-label, adaptive, platform trial with a primary outcome of 28-day mortality [11]. The RCT studied 2,104 patients randomly allocated to receive dexamethasone compared to 4,321 patients concurrently allocated to usual care. CST was associated with a significant reduction in mortality $(21.6 \%$ vs. $24.6 \%)$ with an age-adjusted rate ratio): $0.83 ; 95 \% \mathrm{CI}: 0.74-0.92$; $\mathrm{P}<0.001$ ). Dexamethasone reduced deaths by one-third in the subgroup of patients receiving invasive MV $(29.0 \%$ vs. $40.7 \%$, rate ratio: 0.65 (95\% CI: $0.51-0.82) ; \mathrm{P}<0.001)$, by one-fifth in patients receiving oxygen without invasive $\mathrm{MV}(21.5 \%$ vs. $25.0 \%$, rate ratio: 0.80 (95\% CI: $0.70-0.92) ; \mathrm{P}=0.002)$, but did not reduce mortality in patients not receiving respiratory support at randomization (17.0\% vs. $13.2 \%$, rate ratio: 1.22 (95\% CI: 0.93 - 1.61); $\mathrm{P}=0.14)$. However, it should be noted that dexamethasone is the corticosteroid associated with greater suppression of the adrenal gland. Notably, the RECOVERY RCT utilized a small dose of dexamethasone and did not incorporate tapering to prevent rebound inflammation.

An Italian multicenter, prospective observational study explored the association between exposure to prolonged CST (a pre-designed protocol: methylprednisolone $80 \mathrm{mg}$ for 9 days followed by tapering based on improvement in predefined laboratory parameters) and the need for ICU referral, intubation or death within 28 days (composite primary endpoint) in patients (83 on CST vs. 90 matched control) with severe COVID-19 pneumonia admitted to Italian respiratory highdependency units [44]. The composite primary endpoint was met by 19 vs. 40 (aHR: 0.41; 95\% CI: 0.24 - 0.72). Transfer to ICU and need for invasive MV was necessary in 15 vs. 27 (P $=0.07)$ and 14 vs. $26(\mathrm{P}=0.10)$, respectively. By day 28 , the methylprednisolone group had fewer deaths (6 vs. 21, aHR: 0.29 ; 95\% CI: $0.12-0.73$ ) and more days off invasive MV $(24.0 \pm 9.0$ vs. $17.5 \pm 12.8 ; \mathrm{P}=0.001)$. Study treatment was as- sociated with rapid improvement in $\mathrm{PaO}_{2} / \mathrm{FiO}_{2}$ and C-reactive protein (CRP) levels without affecting lymphocyte count. The complication rate was similar for the two groups $(\mathrm{P}=0.84)$. No difference was observed in viral shedding, determined as the number of days between hospital referral and the first negative nasopharyngeal swab.

A Spanish semi-randomized study investigated methylprednisolone (3 days each, $80 \mathrm{mg}$ and $40 \mathrm{mg}$, respectively) in 85 COVID-19 (56 CST, 29 control) hypoxemic patients; the primary composite outcome was similar to the Italian study [45]. CST was associated with reduced risk of the composite endpoint in the intention-to-treat, age-stratified analysis (combined RR: 0.55 (95\% CI: 0.33 - 0.91); $\mathrm{P}=0.024)$.

The Henry Ford COVID-19 Management Task Force conducted a single pre-test, single post-test quasi-experiment in a multicenter health system in Michigan [35]. They investigated 213 patients with confirmed moderate to severe COVID admitted over a 2 -week period; the first week 81 patients received standard of care (SOC), and the second week 132 patients also received SOC and early initiation of CST (methylprednisolone $0.5-1 \mathrm{mg} / \mathrm{kg} /$ day for 3 days, and longer duration if they required MV). In the first week, half of the patients in the SOC group received CST but with a later initiation. The primary composite outcome was similar to the Italian study, and was reached by fewer patients in the CST group $(34.9 \%$ vs. $54.3 \%, \mathrm{P}=0.005$ ) [46]. This treatment effect was observed within each individual component of the composite endpoint. Significant reduction in median hospital length of stay was also observed in the early corticosteroid group ( 8 vs. 5 days, $\mathrm{P}$ $<0.001)$. Hospital length of stay was decreased by 3 days ( $\mathrm{P}$ $<0.001)$ [35].

It is noteworthy that the initial MATH plus protocol emphasizing the use of methylprednisolone in patients with severe COVID-19 predated the publication of the RECOVERY groups findings.

In the aftermath of the RECOVERY trial, a total of six additional RCTs investigating CST in patients with severe COV- 
Table 2. Review of Corticosteroid Therapy in Patients With COVID-19

\begin{tabular}{|c|c|c|}
\hline $\begin{array}{l}\text { Published RCTs/cohort studies of corti- } \\
\text { costeroid therapy in COVID-19 }\end{array}$ & $\begin{array}{l}\text { Absolute difference in mortality } \\
\text { rate (Rx group vs. control group) }\end{array}$ & $\begin{array}{l}\text { Estimated number needed } \\
\text { to treat to save one life }\end{array}$ \\
\hline Methylprednisolone - hospital patients [54] & $5.9 \%$ vs. $42.9 \%$ & 2.7 \\
\hline Methylprednisolone - ICU patients [44] & $7.2 \%$ vs. $23.3 \%$ & 6.2 \\
\hline Methylprednisolone - hospital patients [35] & $13.6 \%$ vs. $26.3 \%$ & 7.8 \\
\hline Methylprednisolone - ARDS patients [53] & $46.0 \%$ vs. $61.8 \%$ & 6.3 \\
\hline Methylprednisolone - percent on oxygen [36] & $13.9 \%$ vs. $23.9 \%$ & 10.0 \\
\hline \multicolumn{3}{|l|}{ RECOVERY trial (dexamethasone) [51] } \\
\hline Percent on oxygen & $23.3 \%$ vs. $26.2 \%$ & 28.6 \\
\hline Percent on mechanical ventilation & $29.3 \%$ vs. $41.4 \%$ & 8.4 \\
\hline Hydrocortisone - CAPE COVID - ICU patients [60] & $14.7 \%$ vs. $27.4 \%$ & 7.9 \\
\hline
\end{tabular}

Table is provided by Pierre Kory Flccc.org. COVID-19: coronavirus disease 2019.

ID-19 were published. An updated meta-analysis requested by the WHO included patients randomized to receive systemic dexamethasone, hydrocortisone, or methylprednisolone (678 patients) or to receive usual care or placebo (1,025 patients) [47]. Data on mortality found little inconsistency between the trial results $\left(\mathrm{I}^{2}=15.6 \%\right)$ and the summary OR was 0.70 (95\% CI: $0.48-1.01 ; \mathrm{P}=0.053$ ) based on the random-effects meta-analysis. They reported 222 deaths among patients randomized to corticosteroids (32.7\%) and 425 deaths (42.5\%) among patients randomized to usual care or placebo (summary OR: 0.66 (95\% CI: $0.53-0.82)$; $\mathrm{P}<0.001)$. As a result of these findings, the WHO updated their "Corticosteroids for COVID-19: Living Guidance" document recommending "systemic corticosteroids rather than no corticosteroids for the treatment of patients with severe and critical COVID-19 (strong recommendation, based on moderate certainty evidence)" [48]. Additional rationale in support of CST was recently reviewed and presented in Table 2 [35, 36, 43, 44, 49-54].

\section{AA and COVID-19}

Approximately $15 \%$ of patients with COVID-19 infection progress to a respiratory illness, which in its early phase is consistent with OP, and if either not treated or insufficiently treated with corticosteroids progresses to a more severe pneumonitis, with about 5-10\% requiring MV which then further injures the lung and causes ARDS often coincident with a cytokine storm characterized by vasoplegia, hypercoagulability and multiorgan failure [10, 25, 27]. AA is the most potent and important anti-oxidant in mammals with pleiotropic modes of action targeting multiple molecules and biological pathways involved in inflammatory states such as sepsis, ARDS, trauma, and burns [55-57].

A significant body of preclinical and clinical evidence in septic shock and other types of stress responses demonstrate that intravenous AA (IVAA) can attenuate many of the lifethreatening complications of a dysregulated immune system during COVID-19 infection $[27,57,58]$. In contrast to influenza and other respiratory viruses, there is a blunted antiviral response with low interferon (IFN) production and increase in pro-inflammatory cytokines. In a minority of patients, cytokine storm ensues with overwhelming production of proinflammatory cytokines and reactive oxygen species (ROS) leading to progressive organ failure [25, 27, 59-61].

The innate immune and adaptive response provides an essential role in the antiviral response and is mediated by the release of type I IFN- $\alpha / \beta$ by macrophages, lymphocytes and infected immune cells $[59,62]$. Several experiments employing $\mathrm{H} 1 \mathrm{~N} 1$ infected knockout mice unable to synthesize AA found that administration of AA increases IFN production, restores expression of genes necessary for production of IFNs and decreases proinflammatory gene expression with a subsequent decrease in the release of proinflammatory cytokines $[62,63]$. AA is thus an essential factor in the anti-viral immune response during the early phase of virus infection through the production of type I IFNs [62].

AA is also a co-factor for the production of endogenous catecholamines and corticosteroid synthesis [57-70]. Given that humans, due to an evolutionary mutation, are almost unique among all mammals in their inability to synthesize AA, in states of stress plasma AA levels are rapidly and markedly decreased as opposed to other mammals such as goats that immediately begin to produce many grams of AA in stressed or infected states $[57,71,72]$. AA reverses ROS-induced oxidant stress impairment of glucocorticoid receptor function [73, 74]. Thus, AA is synergistic with endogenous and exogenous corticosteroids in reversal of shock [57, 74]. In clinical studies AA given with or without steroids results in decreases in vasopressor requirement and reversal of shock [57, 70, 72, 74]. AA antioxidative and ROS scavenging properties may counteract cytokine, chemokine and inflammatory cell-mediated excessive production of ROS which are known to cause decreased vascular tone and endothelial injury $[72,74]$.

In animal models, IVAA was shown to improve arteriolar responsiveness to vasoconstrictors and decrease microvascular 
permeability $[72,75]$. The hemodynamic effects of AA have been demonstrated in septic shock, trauma, and burns where administration of AA reduced vasopressor and volume resuscitation requirement $[55,57,76,77]$.

Marik et al, in a propensity adjusted study of patients with sepsis, administered IVAA, hydrocortisone, and thiamine in patients with severe sepsis and found a significant survival benefit [55]. CITRIS-ALI, the largest double-blinded placebocontrolled trial of high-dose AA in ARDS patients found that both mortality and decreased ICU length of stay were significantly reduced in the treatment arm [78]. The reasons for the lack of immediate adoption of this therapy in ARDS can only be explained by the fact that the original primary outcome analysis failed to account for all the early excess deaths in the control group, where no severity of illness (SOFA) score was assigned to the patients who died. A subsequent letter to the editor by a group of prominent scientists demanded an analysis accounting for these early deaths. The study authors complied and found that the primary outcome of SOFA score was statistically significantly decreased at $96 \mathrm{~h}$ along with the mortality in the treated group [79]. Thus, CITRIS-ALI, although inexplicably portrayed as a negative trial, was instead profoundly positive in terms of both its primary outcome and important secondary outcomes.

Two large meta-analyses involving critically ill patients demonstrated intravenous vitamin $\mathrm{C}$ administration showed no adverse reactions, reduced the need for fluids and vasopressor support and reduced the length of time on mechanical ventilators $[58,80]$.

Most importantly, a prospective, randomized, doubleblinded, placebo-controlled trial of high-dose IVAA in COVID-19 respiratory failure was conducted at three hospitals in Hubei, China where the intervention group was treated with $12 \mathrm{~g}$ of IV AA every $12 \mathrm{~h}$ for 7 days [81]. The trial was stopped early due to control of the epidemic, thus only 56 patients were included. Although the primary endpoint of invasive MV-free days was not significant ( 26.0 vs. $22.0, \mathrm{P}=0.57$ ), significant improvements in oxygenation and reductions in IL-6 were found in the intervention group over the 7 days and a reduction in 28-day mortality was observed, although the difference was not statistically significant $(22.2 \%$ vs. $37.9 \%, P=0.31)$. In the sub-group of patients with SOFA scores $\geq 3$, the differences in ICU and hospital mortality were statistically significant while the 28-day mortality approached, but did not reach statistical significance $(21.7 \%$ vs. $52.4 \%, \mathrm{P}=0.06)$ [81]. To date, there is only one small RCT involving IVAA demonstrating improved mortality in those patients with an SOFA score $\geq 3$, and there has been accumulating evidence that IVAA improves inflammatory markers, coagulopathic parameters, ameliorates cardiac injury, decreases incidence of systemic inflammatory response syndrome (SIRS) and shortens the duration of SIRS (Table 3) [81-89].

In summary, IVAA was included based on the pleiotropic effects on important physiologic functions, its properties as powerful antioxidant/ROS scavenger, and reversal of ROSinduced oxidant stress impairment of glucocorticoid receptor function, its impact on outcomes in the treatment of both COVID respiratory failure and non-COVID ARDS as well as other hyperinflammatory conditions along with an impeccable safety profile and low cost. Based on the current preclinical and clinical evidence based on Oxford evidence medicine levels of evidence (Oxford Center for Evidence-Based Medicine Levels of Evidence (http://www.cebm.net/?o=1 116), we recommend the use of IVAA as an adjunctive therapeutic in the management of COVID-19 [90].

\section{Thiamine and COVID-19}

Thiamine is a water-soluble vitamin passively absorbed in the small intestine. After ingestion, free thiamine is converted to the active form thiamine pyrophosphate (TPP), commonly known as vitamin B1, by thiamine pyrophosphokinase. The majority of TPP in the body is found in erythrocytes and accounts for approximately $80 \%$ of the body's total storage [91]. TPP is a key co-factor for pyruvate dehydrogenase, the gatekeeper for entry into the Krebs Cycle, without which pyruvate would be converted to lactate as opposed to acetyl-coenzyme A [91].

Multiple other non-cofactor roles of thiamine exist within the immune system, gene regulation, oxidative stress response, cholinergic activity, chloride channel function, and neurotransmission [91]. In experimental rheumatoid arthritis, thiamine increased the ability of corticosteroids to suppress production of tumor necrosis factor (TNF)- $\alpha$ and interleukin-6 (IL-6) [92] .

The human adult can store around $30 \mathrm{mg}$ of thiamine in muscle tissue, liver and kidneys; however, these stores can become depleted in as little as 18 days after the cessation of thiamine intake [91]. A thiamine deficiency syndrome, beriberi, bears a number of similarities to sepsis, including peripheral vasodilation, cardiac dysfunction, and elevated lactate levels [57]. In critical illness, the prevalence of thiamine deficiency is in $10-20 \%$ upon admission and can increase up to $71 \%$ during ICU stay, suggesting rapid depletion of this vitamin $[93,94]$. Based on limited data, no association was detected between thiamine levels, markers of oxidative stress and mortality [94,95].

In one study, a significant negative correlation was reported between thiamine and lactic acid levels in patients with sepsis without liver dysfunction [93]. In a pilot RCT of patients with septic shock $(\mathrm{n}=88)$, the administration of thiamine (200 $\mathrm{mg}$ twice a day for 7 days) reduced lactate levels and improved mortality over time in a pre-defined subgroup of patients with thiamine deficiency (35\% of cohort) [96]. In a retrospective, single-center, matched cohort study, administration of thiamine within $24 \mathrm{~h}$ of septic shock $(\mathrm{n}=123)$ was associated with improved likelihood of lactate clearance and a reduction in 28day mortality [97]. In a randomized study of patients undergoing gastrointestinal surgery, thiamine administration $(200 \mathrm{mg}$ daily for 3 days) was associated with significant reduction in post-operative delirium [98].

It should be noted that the increased secretion of IL-17 by TH17 cells contributes to the proinflammatory cytokine storm characteristic of COVID-19 [99]. In an ex-vivo study, Vatsalya et al demonstrated that $200 \mathrm{mg}$ thiamine/day decreased TH17 cell activation [100].

Sulaiman et al evaluated the use of thiamine as an adjunct to therapy in a propensity matched study involving 738 criti- 


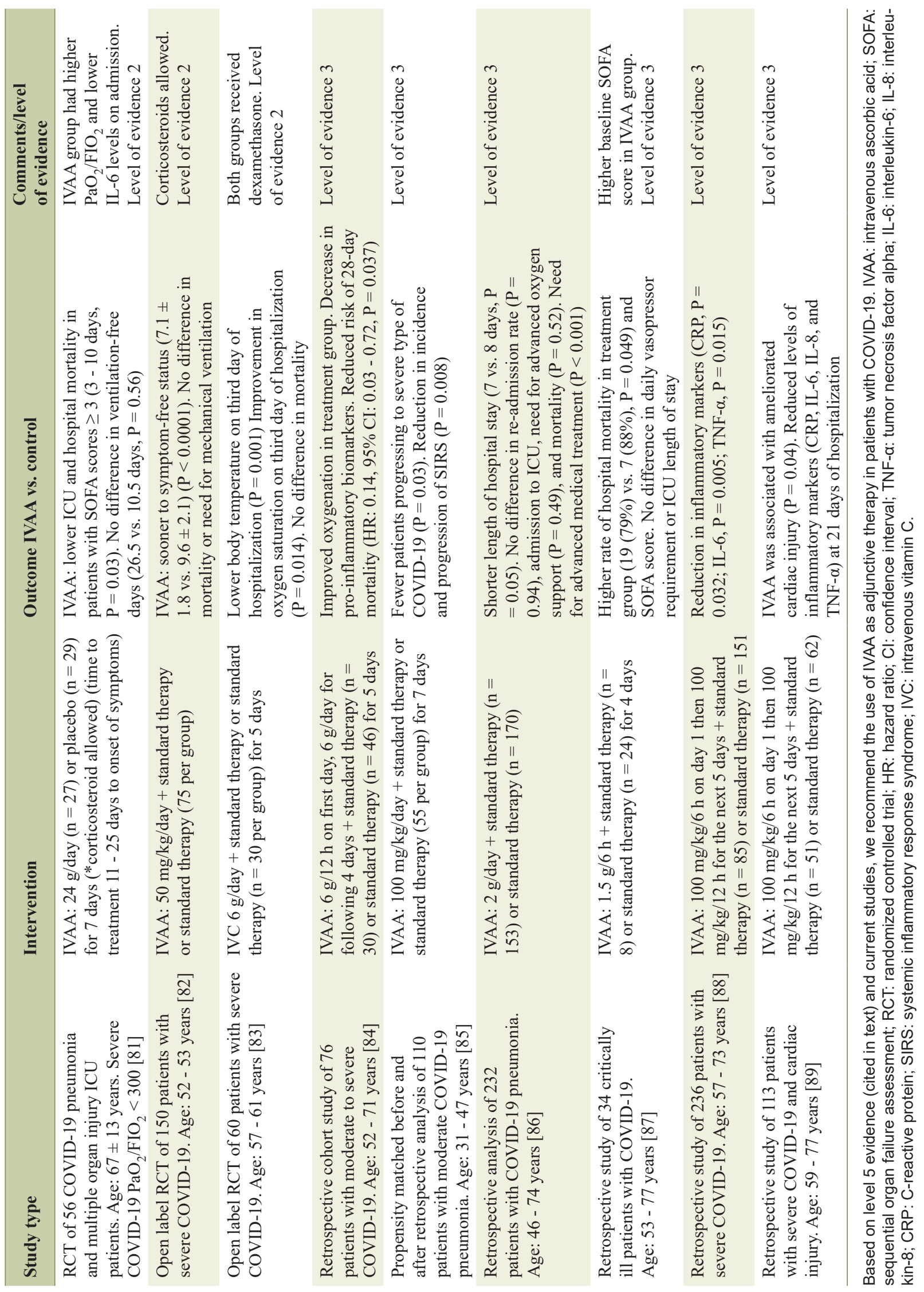


cally ill patients. Propensity matching included 166 patients of whom 83 received thiamine. There was a statistically significant decrease in mortality and incidence of thrombosis in patients receiving thiamine [101].

Given these promising results and favorable safety profile, the MATH + protocol included thiamine supplementation as part of the combination therapy in critically ill COVID-19 patients.

\section{Anticoagulation (AC) and COVID-19}

From the earliest clinical experiences caring for COVID-19 patients, physician reports of excess clotting emerged from China and Italy [102-104]. Infections are recognized activators of inflammatory and coagulation responses as part of the host defense, and in COVID-19, although patients present with prominent elevation of D-dimer and fibrin/fibrinogen degradation products as is typically seen in traditional disseminated intravascular coagulation (DIC), either little or no abnormalities in prothrombin time (PT), partial thromboplastin time (PTT), and platelet counts are seen initially [102]. The term COVID19-associated coagulopathy (CAC) was created to describe these abnormalities in tests, although typical impaired clotting that results in increased bleeding is not observed [102]. Conversely, nearly all published clinical reports describe CAC as a "hypercoagulable" condition.

Thromboelastography (TEG) has best elucidated the hypercoagulable nature of CAC given its ability to assess both the pro-thrombotic and hypocoagulable dynamics of whole blood as it forms clot under conditions of low shear stress. A group including one of the authors (PK) recently published a case series of TEG studies from the first wave of COVID-19 patients encountered which consistently revealed hypercoagulability with rapid and large amplitudes of clot formation with little to no fibrinolytic activity present $[105,106]$. These early insights, along with the large amount of subsequent investigations reviewed below, served as an initial basis for the more aggressive anti-coagulation regimen incorporated within $\mathrm{MATH}+$.

Given that investigations into CAC found severe hypercoagulability, it is unsurprising that the majority of published data report a higher than previously reported frequency of clotting in critically ill COVID-19 patients despite receiving thromboprophylaxis. Helms et al from France reported an incidence of $16.7 \%$ of venous thromboembolism (VTE) (mainly pulmonary embolism (PE)) in their COVID-19 respiratory failure patients, an incidence six-fold higher than a matched population of non-COVID ARDS patients treated a year prior. Equally alarming, $96.6 \%$ of patients on continuous renal replacement therapy developed circuit clotting. In two studies from Holland, the incidence of VTE in ICU patients was up to one-third by day 7 and greater than $50 \%$ after day $14[72,79]$.

In a lower extremity ultrasound screening study of an ICU population with two-thirds on systemic $\mathrm{AC}$ and one-third on thromboprophylaxis, VTE was found in $69 \%$ of the patients, with a $100 \%$ incidence in those on prophylaxis and $56 \%$ in patients on AC [107]. The VTE rates reported in the above ICU populations of COVID-19 patients are magnitudes higher than the approximate $8 \%$ rate of VTE reported in previous studies of non-COVID-19 ICU patients receiving thromboprophylaxis [108].

In contrast to COVID-19 ICU patients, the rates of VTE in COVID-19 hospitalized ward patients have been lower. Middeldorp reported a cumulative $9.2 \%$ incidence of VTE, similar to pre-COVID-19 incidences in non-ICU patients; however, another study found a cumulative incidence of $27 \%$ with $4 \%$ arterial thrombosis resulting in a composite incidence of $29 \%$ $[109,110]$. However, not all studies of hospital ward patients found such high incidences, for instance Lodigiani et al reported a $6.6 \%$ incidence in this population while Cattaneo et al found that in a population of 388 COVID-19 patients, 64 underwent screening leg ultrasound, and no patient developed VTE [111].

In regards to $\mathrm{PE}$ incidences alone, a recent systematic review of PE prevalence in COVID-19 analyzed 52 studies which included 20,523 patients and reported a markedly increased pooled prevalence of $9 \%$ in non-ICU patients and $19 \%$ among ICU patients [112].

In addition to the markedly elevated incidence of "macrovascular" thrombosis, autopsies have also revealed extensive microvascular thromboses, with one report finding severe endothelial injury associated with the presence of intracellular virus and disrupted cell membranes and widespread thrombosis with microangiopathy [113]. Another found that alveolar capillary microthrombi were nine times higher prevalent in COVID-19 patients than patients with influenza $(\mathrm{P}<0.001)$ [114]. Microvascular thrombosis is also a prominent feature in multiple organs, in some cases despite full anticoagulation and regardless of timing of the disease course, suggesting that it plays an early role in causing illness [115]. A recent autopsy series found that in 17 of 25 examined lungs, intravascular fibrin thrombi were found within medium sized arteries or arterioles while in 23 of the 25, platelet aggregates and/or thrombi were found in medium sized arteries, arterioles and capillaries [116]. Even more worrisome were the brain findings where a widespread presence of microthrombi and acute infarction was observed in six of 20 cases. In two of the cases with clinical infarction, there was global anoxic brain injury. Further, in a recent systematic review examining the incidence of stroke in COVID-19, the proportion of COVID-19 patients with stroke (1.8\%, 95\% CI: 0.9-3.7\%) was eight times higher than that reported among hospitalized patients with influenza (0.2\%) [117]. More concerning was the suggestion that these estimates were almost certainly a gross underestimate due to: 1) missed stroke diagnoses in those not extubated and who died; 2) the restrictions on and therefore lack of autopsies; and 3) the well-recognized drop in the number of patients with acute cerebrovascular symptoms seeking medical attention in the COVID-19 era.

Given such high and devastating incidences of macro- and micro-vascular thrombosis in multiple organs among COVID-19 patients, a major clinical question is whether anti-coagulant therapy can improve the outcomes of COVID-19 patients. Tang first reported on 449 patients with "severe" COVID-19 and found that low-molecular weight heparin (LMWH), the majority of the time in prophylactic doses, was associated with a large mortality benefit in the sub-group of patients meeting 
sepsis-induced coagulopathy score $\geq 4(40.0 \%$ vs. $64.2 \%, \mathrm{P}=$ 0.029 ), or D-dimer more than six-fold of upper limit of normal (32.8\% vs. 52.4\%, $\mathrm{P}=0.017$ ) [118]. A large study from Mt. Sinai in New York City on 2,777 patients reported a mortality of $29.1 \%$ in those treated with therapeutic AC compared to $62.7 \%$ who did not receive treatment dose [119]. Another study found that among 49 mechanically ventilated patients, $33 \%$ were diagnosed with $\mathrm{PE}$ and that the use of high-intensity thromboprophylaxis was associated with a lower occurrence of PE $(2 / 18 ; 11 \%)$ than a standard regimen $(11 / 22 ; 50 \%$; OR 0.13 (0.02 - 0.69); $\mathrm{P}=0.02)$ [120].

A retrospective study of 468 hospitalized patients also found that the initial use of high-intensity thromboprophylaxis was associated with improved 30-day mortality (adjusted RR 0.26; 95\% CI: 0.07 - 0.97; P = 0.04) without a significant increase of bleeding [121]. The now largest cohort study of 4,389 patients found that both prophylactic and therapeutic ACs were associated with an absolute decrease of in-hospital mortality and intubation by almost $50 \%$ and $30 \%$, respectively [122]. Among the sub-group of patients $(n=1,860)$ initiated on $\mathrm{AC}$ within $48 \mathrm{~h}$ of admission, therapeutic AC was associated with lower in-hospital mortality than prophylactic $\mathrm{AC}$, although the difference was not statistically significant (aHR 0.86 ; 95\% CI: $0.73-1.02 ; \mathrm{P}=0.08)$. Interestingly, rates of major bleeding were similar on therapeutic AC (27/900, 3.0\%) as compared to patients on prophylactic AC (33/1,959, 1.7\%) and no AC $(29 / 1,530,1.9 \%)$. Jonmarker et al compared the outcomes of COVID-19 ICU patients treated with standard, intermediate, and full-dose AC [123]. They found that mortality was lower in high dose (13.5\%) vs. medium dose $(25.0 \%)$ and low dose thromboprophylaxis $(38.8 \%)$ groups $(\mathrm{P}=0.02)$.

The first RCT comparing therapeutic AC to standard thromboprophylaxis in COVID-19 ICU patients on MV (HESACOVID) was recently published, and although small, reported statistically significant improvements in oxygenation, liberation from MV (HR: 4.0 (95\% CI: 1.035 - 15.053), P = 0.031 ), and ventilator-free days (15 days (IQR 6 - 16) versus 0 days (IQR $0-11), \mathrm{P}=0.028)$ in patients treated with therapeutic doses of AC [124].

In contrast the REMAP-CAP, ACTIV-4a and the ATTACC, the largest prospective international platform studies employing Bayesian analytics demonstrated that in critically ill patients defined as ICU level of respiratory-cardiac support either in an ICU or non-ICU floor, the administration of systemic $\mathrm{AC}$ with therapeutic dose heparin compared to heparin thromboprophylaxis resulted in no improvement in clinical outcomes [125]. Conversely, in non-critically ill COVID-19 patients, systemic AC with therapeutic dose heparin compared to thromboprophylaxis resulted in improved survival, and decreased need for cardiorespiratory support [126]. Based on these findings, the initial MATH+ has been modified to recommend unless otherwise indicated that systemic AC with therapeutic dose heparin be reserved for non-critically ill COVID-19 patients and thromboprophylaxis be instituted in critically ill. Systemic heparinization should be continued if the non-critically progress to requiring ICU level of care.

Although it is encouraging that the initial MATH+ protocolrecommended treatment dose AC for COVID-19 ICU patients has now been strongly associated with improved survival, what is worrisome are the multiple reports of "coagulation failure" in which severe thrombotic complications occurred in COVID-19 patients despite therapeutic AC [107, 109, 127]. A possible explanation for this phenomenon was provided by Maier et al, where they used capillary viscometry in 15 severely ill COVID-19 ICU patients, almost all in ARDS, and found that all patients had a blood viscosity exceeding 95\% of normal, a condition they termed "COVID-19 associated hyperviscosity" [128]. The four patients with the highest viscosity all suffered thrombotic complications despite the majority of patients having been on either systemic AC or intermediate dose prophylaxis. Given that hyperviscosity is thought due to increased plasma proteins such as fibrinogen or immunoglobulin which then damage endothelium, this suggests that therapeutic plasma exchange (TPE) may play a role [129]. The growing body of evidence strongly supporting the role of TPE in COVID-19 is reviewed below in the section "Salvage therapy".

To the best of our knowledge, no major national or international medical society to date has recommended therapeutic $\mathrm{AC}$ be administered as standard practice in any sub-group of COVID-19 patients. Many have instead recommended standard thromboprophylaxis for all hospitalized patients with COVID-19 while also avoiding a recommendation for even highintensity thromboprophylaxis. This therapeutic conservatism is puzzling, given that, based on the best available evidence to date, the incidence and risks of the now well-described severe hypercoagulability appear to far outweigh the risks of even a slightly more aggressive AC regimen, based on the large magnitude of survival associated with therapy and the paucity of reports of significantly increased bleeding complications [118, 119]. Thus we believe that, in hospitalized patients, an aggressive thromboprophylaxis in critically ill patients and therapeutic dose $\mathrm{AC}$ be administered in non-critically ill patients unless specifically contraindicated.

The "intermediate" dose thromboprophylaxis we recommend in ICU patients is based on pharmacokinetic and antiXa level monitoring studies and suggests use of weight-based prophylaxis with $0.5 \mathrm{mg} / \mathrm{kg}$ twice daily of LMWH [130]. In regards to patients with impaired renal function particularly in those with creatinine clearances of less than $30 \mathrm{~mL} / \mathrm{min}$, there is currently conflicting literature on dosing as in some preparations, there is risk of accumulation [131]. We therefore recommend monitoring anti-Xa levels in this subset of patients and the use of unfractionated heparin in patients on dialysis or those with creatinine clearances of less than $10 \mathrm{~mL} / \mathrm{min}$.

In non-ICU patients, we recommend treatment dose $\mathrm{AC}$ be provided using $1 \mathrm{mg} / \mathrm{kg}$ LMWH twice daily. Further, we recommend monitoring of anti-Xa levels aiming for an anti-Xa activity of $0.6-1.1 \mathrm{IU} / \mathrm{mL}$ due to reports that heparin resistance appears to be common in COVID-19 [132]. In addition, due to augmented renal clearance, COVID-19 patients may have reduced antiXa activity despite standard dosages of LMWH [133].

\section{Melatonin and COVID-19}

Melatonin (N-acetyl-5-methoxytryptamine) is synthesized from tryptophan in the pineal gland and in the mitochondria of almost all cells in the body [134]. Melatonin is released 
Table 4. Clinical Studies Involving Melatonin in the Treatment of COVID-19

\begin{tabular}{|c|c|c|c|}
\hline Trial details & Dose & Outcomes & Comments/level of evidence \\
\hline $\begin{array}{l}\text { Randomized single blind trial. Treatment: } \\
\mathrm{n}=14 . \text { Control: } \mathrm{n}=17 . \text { Age: } 25 \text { - } 65 \text { years. } \\
\text { Hospitalized mild moderate COVID- } 19 \text { [145] }\end{array}$ & $\begin{array}{l}6 \mathrm{mg} \text { melatonin at } \\
\text { bedtime for } 14 \text { days }\end{array}$ & $\begin{array}{l}\text { Improved declined CRP in } \\
\text { treatment group. Percentage of } \\
\text { recovery (based on symptoms) in } \\
\text { patients who took melatonin was } \\
\text { higher than that of patients in the } \\
\text { control group }(85.7 \% \text { vs. } 47.1 \%)\end{array}$ & $\begin{array}{l}\text { Corticosteroids given. } \\
\text { Level of evidence } 2\end{array}$ \\
\hline $\begin{array}{l}\text { Randomized open label study. Treatment: } \\
n=48 \text {. Control: } n=48 \text {. Age: } 36 \text { - } 69 \text { years. } \\
\text { Mild to moderate COVID-19 [147] }\end{array}$ & $\begin{array}{l}3 \mathrm{mg} \text { at bedtime } \\
\text { for } 7 \text { days }\end{array}$ & Improvement in oxygenation & $\begin{array}{l}\text { Higher usage of } \\
\text { methylprednisolone in control } \\
\text { group. Level of evidence } 2\end{array}$ \\
\hline $\begin{array}{l}\text { Retrospective study. Patients: } \mathrm{n}= \\
\text { 791. Mean age: } 56 \text { years. Patients } \\
\text { received melatonin: } \mathrm{n}=112[148]\end{array}$ & $\begin{array}{l}112 \text { patients } \\
\text { received melatonin }\end{array}$ & $\begin{array}{l}\text { Improved survival in those } \\
\text { patients who received melatonin }\end{array}$ & $\begin{array}{l}\text { Study adjusted for } \\
\text { comorbidities and therapy } \\
\text { including corticosteroids. } \\
\text { Level of evidence } 3\end{array}$ \\
\hline
\end{tabular}

Based on level 5 evidence (cited in text) and current studies, we recommend the use of melatonin as adjunctive therapy in patients with COVID-19. CRP: C-reactive protein.

from the pineal gland into the systemic circulation, achieving plasma concentration between 80 and $120 \mathrm{pg} / \mathrm{mL}$ at night and $10-20 \mathrm{pg} / \mathrm{mL}$ during the day. Melatonin binds to two receptor subtypes: MT1 and MT2 [135]. The melatonin receptors are G-protein coupled receptors (GPCRs) which both activate and inhibit a constellation of intracellular signaling pathways.

In addition to its role in regulating the circadian rhythm, melatonin is a potent anti-oxidant and immune regulator that controls both the innate and adaptive immune response [134, 136]. The anti-oxidative effect of melatonin cooperates with its anti-inflammatory actions by up-regulating anti-oxidative enzymes (e.g. superoxide dismutase), down-regulating pro-oxidative enzymes (e.g. nitric oxide synthase), and by interacting directly with free radicals, functioning as free radical scavenger $[134,137]$. Melatonin plays an important role in protecting the mitochondria from oxidative injury, thereby playing a critical role in maintaining energy production [134]. Melatonin has significant anti-inflammatory, anti-apoptotic properties, and anti-NF- $\kappa \mathrm{B}$ activation and has been demonstrated to reduce pro-inflammatory cytokines levels [138-141].

Melatonin levels fall off dramatically after age 40; these are also the patients at highest risk of developing COVID-19 and from dying from the disease $[142,143]$.

SARS-CoV-2-induced endothelial dysfunction is initiated by increases in the phosphorylation levels of JAK2 and STAT3, producing increased amounts of ROS [144]. These changes can be reversed by administration of melatonin by abating the production of superoxide anion, hydrogen peroxide and peroxynitrite [138]. The clinical utility of melatonin in COVID-19 was first demonstrated in a large prospective registry created to identify risk factors for the development of a positive SARS-CoV-2 test [16]. Researchers found that the most potentially impactful intervention to lower risk of testing positive was if patients were taking melatonin, paroxetine, or carvedilol, all medications that had been previously identified in drug-repurposing studies to have specific activity and potential benefit against SARS-CoV-2 [16, 141].

Oral melatonin use by humans is exceedingly safe, with only minor side effects such as headache and drowsiness. The lethal dose 50 (LD 50) of melatonin is reported to be infinity, i.e., it is impossible to administer a large enough dose of melatonin to kill an animal. It should be noted that there is marked variability in first-pass hepatic metabolism, resulting in marked unpredictability in serum levels [144]. Furthermore, the optimal dose of melatonin in "healthy individuals" and those with inflammatory disorders is unknown. For patients with COVID-19 we suggest a dose of $6-12 \mathrm{mg}$, taken at night [138]. However, a dose of up to $400 \mathrm{mg}$ has been suggested [140]. To date, there have been three randomized trials demonstrating that melatonin use leads to quicker time to recovery, decrease in CRP levels and improved oxygenation level (Table 4) [145-147]. In addition, a retrospective study of 791 patients revealed that melatonin exposure post intubation was associated with improved survival (Table 4) [148].

Based on the level of evidence (Oxford Center for Evidence-Based Medicine Levels of Evidence (http://www.cebm. net/?o=1116), we recommend the use of melatonin as adjunct to therapy.

\section{Zinc and COVID-19}

Zinc likely plays an important role in the prophylaxis of COVID-19, in the treatment of the early symptomatic phase, and in limiting the immune dysregulation and associated cytokine storm in the pulmonary phase [149]. Zinc is a nutritionally fundamental trace element and is the second most abundant trace metal in the human body after iron. Since zinc does not have a major storage depot in the body, zinc deficiency is easily and rapidly produced. It should be recognized that the same dietary 
factors leading to deficiency of zinc frequently result in the deficiency of other micronutrients. Zinc plays an important role in the host's anti-viral (and antibacterial) immune response. In addition, zinc is directly viricidal. Zinc is a component of over 1,000 transcription factors, including DNA binding proteins and is required in over 300 metalloenzymes. Zinc plays a central role in cellular differentiation and proliferation, and its deficiency causes impaired immune response, increased susceptibility to infections and impaired wound healing [150, 151]. Zinc is necessary for optimal functioning of both innate and adaptive immunity. Zinc status strongly affects T- and Blymphocyte function and antibody formation [150]. Impaired immune function due to inadequate zinc status may be the most common cause of secondary immunodeficiency in humans. Zinc deficiency is an important public health problem affecting 2 billion people worldwide, including a considerable proportion of the Western population [150, 152-154]. Zinc levels are reported to be very low in critically ill patients, particularly those with sepsis and acute respiratory failure $[151,155$, 156]. Low zinc levels have been reported to be associated with recurrent infections and increased hospital mortality [157]. In addition, zinc deficiency has been demonstrated to potentiate ventilator-induced lung injury [158].

Previous studies have demonstrated the benefit of zinc supplementation in viral infections, most notably upper respiratory tract infections. Meta-analyses of RCTs have demonstrated that zinc lozenges at a dose of $\geq 75 \mathrm{mg} /$ day (elemental zinc) administered within $24 \mathrm{~h}$ of onset of symptoms and taken for at least 5 days significantly reduced the duration of common cold symptoms, school absence and the use of antibiotic $[159,160]$. Trials of low dose zinc lozenges $(<75 \mathrm{mg} /$ day zinc) found no effect on the duration of colds. However, when combined with vitamin $\mathrm{C}$, low-dose zinc was reported to reduce the duration of symptoms of the common cold [154]. When used prophylactically for at least 5 months, zinc lozenges at a dose $\geq 75 \mathrm{mg} /$ day reduced the risk of developing a common cold. Zinc supplementation of nursing home elderly patients was reported to reduce the incidence of pneumonia [161]. Adverse events of zinc lozenges include a bad taste and increased incidence of nausea.

Te Velthuis and colleagues demonstrated that zinc together with the zinc ionophore pyrithione inhibited the activity of the SARS-CoV RNA-dependent RNA polymerase blocking viral replication in a cell culture [162]. It should be noted that both hydroxychloroquine and the plant phytochemical quercetin are zinc ionophores $[163,164]$. However, the role of zinc with or without the addition of zinc ionophores in the treatment of COVID-19 remains speculative [165].

\section{Selective Serotonin Reuptake Inhibitors (SS- RIs) and COVID-19}

SSRIs, particularly fluvoxamine and fluoxetine have demonstrated promise as repurposed agents in the management of COVID-19. The administration of these agents is associated with a decrease in the release of pro-inflammatory cytokines IL-6, IL-10, TNF- $\alpha$ and CCL2 [166]. SSRIs particularly flu- voxamine and fluoxetine possess pleotropic effects such as inhibiting the SR1 potentially attenuating the cytokine storm. Some SSRIs inhibit acid sphingomyelinase activity which may prevent viral entry into epithelial cells [166-168]. In addition, SSRIs inhibit platelet activation thus potentially preventing endothelial injury and microthrombosis [166]. A placebo control double-blinded randomized double-blinded study demonstrated that the administration of fluvoxamine at a dose of 300 mg per day decreased hospitalization rates [169].

The large randomized placebo-controlled platform TOGETHER trial revealed that $100 \mathrm{mg}$ of fluvoxamine two times a day for 10 days was effective in reducing the need for hospitalization in high risk outpatients with COVID-19 [170]. Recently, a large retrospective study conducted by Hoertel et al revealed that use of antidepressants particularly SSRIs was significantly associated with a reduction in mortality and need for MV [167].

\section{Anti-Androgen Therapy and COVID-19}

Male sex, particularly those with androgenetic alopecia (AGA) [171-175], users of anabolic-androgenic steroids (AAS) [176], hypersensitivity of the androgen receptor (AR) [177, 178], and women with hyperandrogenic states are known independent risk factors for COVID-19 [179, 180]. In contrast, users of anti-androgen agents, in particular those under androgen deprivation therapy (ADT) for castration-resistant prostate cancer, and males with prostate cancer have lower risk compared to age-adjusted males without prostate cancer [181-185]. These observations are supported by the molecular mechanisms of SARS-CoV-2 cell entry is highly dependent on androgen activity $[186,187]$. In addition, there is a strong correlation between SARS-CoV-2 concentration and damage, and androgen activity $[188,189]$. These findings support the hypothesis that antiandrogens could be effective against COVID-19 with observational and RCTs in early COVID-19 have demonstrated that dutasteride, spironolactone and proxalutamide could protect against COVID-19 disease progression [190-195]. These benefits have also been observed in hospitalized patients through RCTs for finasteride and proxalutamide [191, 193, 194, 196, 197]. Thus, the strong biological plausibility of androgen-dependent mechanisms of SARS-CoV-2 cell invasion, the multiple corresponding epidemiological observations in both excess and blockage of androgen activity, observational, and several RCTs demonstrating the efficacy of a variety of anti-androgens in preventing COVID-19 disease progression support the recommendation for their use during hospitalization.

Anti-androgen treatment during hospitalization must be done for at least 12 - 14 days, since earlier interruptions can lead to severe relapse, rapid disease progression and high mortality rate [198].

\section{Vitamin D and COVID-19}

Vitamin D is obtained via the diet or produced in the skin by UVB light. Aside from its known role in calcium metabolism 
and bone health, it also has important roles in the immune system including support of endothelial barriers, and innate and adaptive immunity [199]. The innate immune system in COVID-19 produces both pro-inflammatory and anti-inflammatory cytokines while vitamin $\mathrm{D}$ reduces the production of pro-inflammatory Th1 cytokines such as TNF- $\alpha$ and IFN- $\gamma$ and increases the expression of anti-inflammatory cytokines by macrophages [200-202].

Given its important roles in immune function, many have hypothesized that vitamin D deficiency increases susceptibility to infections and that supplementation may improve outcomes, particularly in COVID-19 [203, 204]. Data supportive of the theory that deficiency leads to infections largely rest on the fact that seasonal influenza infections generally peak in conjunction with times of the year when $25(\mathrm{OH}) \mathrm{D}$ concentrations are lowest [205]. Further, the onset of the epidemic and higher case load in countries during the winter season also raises the possible association with low vitamin D status [206]. Rhodes et al first identified this link by comparing the mortality of COVID-19 in relation to country latitude and found that, even after adjusting for age, there was a $4.4 \%$ increase in mortality for each degree latitude north of $28^{\circ}$. Further, ethnic minorities in both the United States of America and the United Kingdom have high rates of vitamin D deficiency, potentially explaining why the mortality rates in these populations are much higher. Recently, strong evidence supporting a prophylactic role of vitamin D supplementation in COVID-19 comes from a large observational analysis of de-identified tests from a national laboratory which included over 190,000 patients from all 50 states. They analyzed SARS-CoV-2 test results among patients with a vitamin $\mathrm{D}$ level drawn at some point in the previous 12 months. The SARS-CoV-2 positive test rates among three vitamin D range levels were as follows: $12.5 \%$ if "deficient" $(<20 \mathrm{ng} / \mathrm{mL}), 8.1 \%$ if "adequate" (30 - $34 \mathrm{ng} / \mathrm{mL})$, and $5.9 \%$ if the level was above $55 \mathrm{ng} / \mathrm{mL}$ [207].

Given the strong associations of vitamin D deficiency with higher rates of viral infections, multiple studies have tested whether vitamin $\mathrm{D}$ supplementation can reduce this risk. Although studies have conflicted in their findings, a recent meta-analysis from 2018 found that regular supplementation with vitamin D decreased the risk of acute respiratory tract infections, with the most profound effects in patients with severe vitamin D deficiency [208].

The risk of vitamin D insufficiency and the benefits of preillness supplementation were most recently highlighted in an Iranian study of 235 patients with vitamin D levels measured on admission [209]. They found that of the patients with severe COVID-19, 67.2\% had vitamin D insufficiency. Further, the mortality rates of patients over 40 with and without sufficient vitamin D were $9.7 \%$ vs. $20 \%$, suggesting that vitamin D serves an important role in modulating the immune response.

In the ICU, vitamin D deficiency is common and levels decrease rapidly after admission [210, 211]. Further, deficiency has strong negative correlations with outcomes, namely higher mortality [212, 213]. Multiple, initial studies of vitamin D supplementation in critically ill populations were conducted and included in a 2017 meta-analysis that found a statistically significant effect in reducing mortality [214, 215]. However, more recently, the results of a large, prospective, multi-na- tional, double-blinded, placebo-controlled trial (VIOLET) on the effects of cholecalciferol supplementation in vitamin D deficient critically ill patients were published [216]. The study results, surprisingly, were profoundly negative in that no benefits were found of giving a large single dose supplement given around the time of admission into the ICU. Further, no benefits were found in any individual sub-group, even among those with more severe illness or with more severe deficiency.

Although the findings of the VIOLET trial strongly suggest that vitamin D supplementation alone has no benefit as an intervention in the critically ill, our inclusion of vitamin D in COVID-19 treatment, aside from the evidence suggesting the possibility of a more potent therapeutic role in both viral syndromes and COVID-19 (likely few patients with viral syndromes were included in the VIOLET study), is largely based on the therapeutic enhancement of corticosteroid effect when co-administered with vitamin D, similar to the synergistic effects of corticosteroids with vitamin C [217]. Investigators have demonstrated that vitamin D up-regulates glucocorticoid receptors which leads to increased T-cell apoptosis while it can also enhance the corticosteroid effect on and suppression of cytokine production in peripheral blood cell monocytes [218-220].

Recently, in a pilot RCT of vitamin D therapy in hospitalized COVID-19 patients using calcifediol, the direct precursor to the active form of vitamin D in the serum, patients were treated on the day of admission with an oral dose of 0.532 mg (roughly equivalent in potency to a dose of 68,000 IU of vitamin $\mathrm{D}_{3}$ ), then they gave half the dose on day 3 , day 7 , and weekly thereafter. They found that of the 50 patients treated with calcifediol, one required admission to the ICU (2\%) while of 26 untreated patients, 13 required admission to the ICU $(50 \%)(\mathrm{P}<0.001$, OR $0.02(0.002-0.17))$ [14]. None of the treated patients died while two control group patients died. The authors concluded that calcifediol seems to reduce the severity of the disease, but larger trials will be required to provide a more definitive answer.

Thus, available data suggest that high-dose vitamin D supplementation is beneficial not only in the prevention of viral infections but also in COVID-19 and in improving the effects of corticosteroid therapy.

Although the impact of supplementation varies by deficiency status as well as severity of illness, vitamin D supplementation is safe; one meta-analysis of healthy patients found no adverse events, while in the critically ill, mild hypercalcemia was the most common adverse effect [208, 221].

Serum levels greater than $50 \mathrm{nmol} / \mathrm{L}(20 \mathrm{ng} / \mathrm{mL})$ are thought sufficient for protection against acute respiratory tract infections [208]. It should be noted that the predominant form of supplementation in North America is vitamin $\mathrm{D}_{2}$ (ergocalciferol) and in Europe it is vitamin $\mathrm{D}_{3}$ (cholecalciferol), although the dosing is the same. One report found that "doses up to $10,000 \mathrm{IU} /$ day is safe, although well above what is needed" and that "only 1,000 - 2,000 IU may be needed to obtain optimal effects on bone and immunity" [222]. Thus to reduce the risk of infection, one expert recommended that people at risk of COVID-19 consider taking 10,000 IU/day of vitamin $\mathrm{D}_{3}$ for a few weeks to rapidly raise $25(\mathrm{OH}) \mathrm{D}$ concentrations, followed by $5,000 \mathrm{IU} /$ day. The goal should be to raise $25(\mathrm{OH}) \mathrm{D}$ concentrations above 40 - $60 \mathrm{ng} / \mathrm{mL}(100-150 \mathrm{nmol} / \mathrm{L})$ [222]. 
Table 5. Clinical Studies Involving Vitamin D Therapy in COVID-19

\begin{tabular}{|c|c|c|c|}
\hline Trial details & Dose & Outcomes & Comments \\
\hline $\begin{array}{l}\text { Randomized single blind } \\
\text { trial. Treatment: } \mathrm{n}=14 \\
\text { Control: } \mathrm{n}=17 . \text { Age: } 25-65 \\
\text { years. Hospitalized mild } \\
\text { COVID-19. Mean age } 51 \pm \\
15 \text { years, healthy cohorts no } \\
\text { comorbidities. Asymptomatic } \\
\text { to mild COVID-19 [225] }\end{array}$ & $\begin{array}{l}\text { Oral cholecalciferol } 60,000 \\
\text { IU daily for } 7 \text { days (if target } \\
25(\mathrm{OH}) \mathrm{D} \text { concentration }>50 \\
\text { ng/mL not achieved on day } 7 \text {; } \\
\text { same dose continued, if target } \\
\text { achieved weekly } 60,000 \text { IU) }\end{array}$ & $\begin{array}{l}\text { Significant rapid disappearance of } \\
\text { viral mRNA in treatment group at } \\
21 \text { days ( } 62 \% \text { vs. } 20 \%) \text { significant } \\
\text { decrease in fibrinogen. No difference in } \\
\text { procalcitonin, CRP, ferritin or D-dimer }\end{array}$ & $\begin{array}{l}\text { Level of evidence } \\
\text { 2. Placebos were } \\
\text { not identical }\end{array}$ \\
\hline $\begin{array}{l}\text { Double masked randomized open } \\
\text { label trial. Treatment: } n=50 \text {. } \\
\text { Control: } n=26 \text {. Age: } 43-63 \text { years. } \\
\text { Moderately severe COVID-19 [14] }\end{array}$ & $\begin{array}{l}\text { Oral calcifediol } 0.532 \\
\text { mg on day of admission } \\
\text { and } 0.266 \text { on day } 3,7 \text { and } \\
\text { weekly until discharge }\end{array}$ & $\begin{array}{l}\text { Need for ICU admission was lower in the } \\
\text { group receiving intervention ( } 2 \% \text { vs. } 50 \% \text {, } \\
\mathrm{P}<0.001 \text { ). Two patients in control group } \\
\text { died, none in the intervention group died }\end{array}$ & Level of evidence 2 \\
\hline $\begin{array}{l}\text { Randomized open label study. } \\
\text { Treatment: } n=44 \text {. Control: } n= \\
\text { 43. Age: } 20-83 \text { years. Vitamin } \\
\text { level less than } 30 \text {. Mild to } \\
\text { moderate COVID-19 [226] }\end{array}$ & $\begin{array}{l}\text { Cholecalciferol } 60,000 \text { IU } \\
\text { daily for } 8 \text { days in participants } \\
\text { with BMI } 18-25 \mathrm{~kg} / \mathrm{m}^{2} \\
\text { and } 10 \text { days for participants } \\
\text { with BMI }>25 \mathrm{~kg} / \mathrm{m}^{2}\end{array}$ & $\begin{array}{l}\text { Significant reduction of inflammatory } \\
\text { markers (CRP, LDH, ferritin, IL- } \\
6, \mathrm{~N} / \mathrm{L} \text { ratio) in intervention group } \\
\text { compared to control group. No } \\
\text { difference in hospital stay or mortality }\end{array}$ & $\begin{array}{l}\text { Level of evidence } 2 . \\
\text { Adjustment made } \\
\text { for comorbidities }\end{array}$ \\
\hline $\begin{array}{l}\text { Double blind randomized } \\
\text { trial. Treatment: } \mathrm{n}=119 \text {. } \\
\text { Control: } \mathrm{n}=118 . \text { Mean age: } \\
56 \pm 15 \text { years. Moderate to } \\
\text { severe COVID-19 [227] }\end{array}$ & $\begin{array}{l}\text { Single dose of oral } \\
\text { cholecalciferol } 200,000 \mathrm{IU}\end{array}$ & $\begin{array}{l}\text { No significant difference between groups } \\
\text { in median length of hospital stay ( } 7 \mathrm{vs} .7 \text {, } \\
\mathrm{P}=0.94) \text {, mortality }(7.6 \% \mathrm{vs} .5 .1 \%, \mathrm{P}= \\
0.43) \text {. No significant difference in need } \\
\text { for ventilation or length of ventilation. No } \\
\text { significant difference in post-hoc analysis } \\
\text { on patients with vitamin D deficiency. }\end{array}$ & $\begin{array}{l}\text { Level of evidence } 2 . \\
\text { Patient could enroll } \\
\text { for up to } 10 \text { days } \\
\text { from development of } \\
\text { symptoms; } 60 \% \text { of } \\
\text { patients in both groups } \\
\text { received corticosteroids }\end{array}$ \\
\hline
\end{tabular}

Based on level 5 evidence (cited in text) and current studies we recommend use of vitamin $\mathrm{D}$ as adjunctive therapy. BMI: body mass index; CRP: C-reactive protein; LDH: lactate dehydrogenase; ICU: intensive care unit; IL-6: interleukin-6.

In the critically ill, the doses used from published RCTs ranged from 200,000 to $600,000 \mathrm{IU}$ of vitamin $\mathrm{D}_{3}$, generally in a single enteral dose [214, 223, 224]. Based on the Castillo et al's trial of calcifediol in COVID-19, in hospitalized patients, we recommend either the same doses of calcifediol be used or the equivalent doses with cholecalciferol. In the ICU, we favor a single large dose of 480,000 IU (30 mL) similar to the prior ICU trials above (Table 1). The vitamin D level should then be re-checked on day 5 , if $<20 \mathrm{ng} / \mathrm{mL}$, a supplemental dose of $96,000 \mathrm{IU} /$ day for 5 days should be given. In summary, clinical data have demonstrated that in some studies vitamin D administration during infection may reduce inflammatory markers, more rapid viral clearance, and decrease admission to the ICU (Table 5) [14, 225-227].

Based on the level of evidence (Oxford Center for Evidence-Based Medicine Levels of Evidence (http://www.cebm. net $/ \mathrm{o}=1116$ ), we recommend the use of vitamin $\mathrm{D}$ as adjunct to therapy.

\section{Statin Therapy and COVID-19}

Statins are medicines that lower lipid levels but also have multiple anti-inflammatory actions. Over a decade of observational studies, both matched and non-matched, showed largely consistent benefits in patients with sepsis and/or ARDS [228]. Multiple RCTs were then conducted using various statins and doses; however, in a well-conducted meta-analysis of RCTs in sepsis involving 2,628 patients, no difference in mortality between groups was found [229]. Similarly, in ARDS trials, a meta-analysis from 2016 found no difference in important outcomes [230]. However, in an editorial that reviewed the outcomes from the STATInS and HARP-2 trials, they found that an alteration of just three events would have yielded statistically significant results in favor of statin use based on mortality outcomes [231-233]. This low "fragility index" suggests that benefits in subgroups exist but are then "lost" in the heterogenous populations that are often included in RCTs of critical illness syndromes such as ARDS and sepsis. This hypothesis was seemingly validated by a secondary analysis of the HARP-2 trial in which the authors split patients into two phenotypes of ARDS, a "hyperinflammatory" and "hypoinflammatory" type [234]. The hyperinflammatory group had higher values of sTNFr-1 and IL-6, lower platelet counts, more vasopressor use, fewer ventilator free days and much higher 28-day mortality. When the hyperinflammatory phenotype received simvastatin $80 \mathrm{mg}$, a large and statistically significant reduction in mortality was found. Further, in COVID-19, two retrospective studies have demonstrated a strong association of statin use with survival. In a large study of 13,981 patients in China, among which 1,219 received statins, the all-cause mortality was almost halved in the statin-treated patients (HR: 0.58 (95\% CI: $0.43-0.80, \mathrm{P}=0.001)$ [13]. In a smaller study in the USA, one group found that among a group of 88 patients, 
$55 \%$ of whom died, atorvastatin use was associated with a $73 \%$ lower risk of progression to death (aHR: 0.38 (95\% CI: 0.18 $-0.77, \mathrm{P}=0.008$ ) [235]. Thus, given the frequent hyperinflammation and elevated levels of IL-6 in COVID-19 respiratory failure, it appears reasonable to employ statin therapy. Atorvastatin is favored due to its more favorable drug-interaction profile and a higher dose of $80 \mathrm{mg}$ should be used, similar to the HARP-2 trial.

\section{Famotidine and COVID-19}

Famotidine, a histamine-2 receptor antagonist (H2RA), although commonly used to suppress acid production in the stomach, is also known to have in-vitro properties which not only inhibit viral replication such as in HIV but also exert stimulatory effects on almost all immune cells of the innate and adaptive immune system [236]. It can also prevent H2R cytokine inhibition and prevent inhibition by histamine on Th-1 cytokine release [237, 238].

H2RAs have proven effective in the past against other viruses. Cimetidine, and less so famotidine exhibited reduced viral infection with HIV in vitro, increased the clearance of warts caused by human papilloma virus, and appeared effective in improving the symptoms associated with chronic Epstein-Barr virus infection [239-241]. In fact, ranitidine bismuth citrate effectively inhibited the nucleoside triphosphate hydrolase and DNA unwinding activities of the SARS coronavirus helicase and dramatically reduced its replication levels in infected cells [242].

Given prior evidence of anti-viral, and in particular antiSARS-CoV and immune system effects, Freedberg et al performed a retrospective cohort study using propensity score matching in COVID-19 patients at a single medical center. The treatment group all received famotidine within $24 \mathrm{~h}$ of admission. A total of 1,620 patients were included with 81 having received famotidine. They found that the use of famotidine was associated with a large reduced risk for death or intubation (aHR: 0.42 , 95\% CI: $0.21-0.85$ ) and also with reduced risk for death alone (aHR: 0.30, 95\% CI: 0.11 - 0.80) [243]. An interesting associated finding was that in patients on proton pump inhibitors, no reduced risk for any patient outcomes was observed. Although an observational study, propensity score matching was performed between groups, and a large difference in intubation and death was observed. Although such a study should be strictly considered as hypothesis generating only with the need for an RCT to optimally validate, in the interim, given the biologic plausibility, prior efficacy against other viruses along with a well-known safety profile, low cost, high availability and potentially large associated reduction in mortality, use of famotidine in the treatment of COVID-19 appears reasonable. Doses used in the Freedberg study were 10 $\mathrm{mg}$ in $17 \%, 20 \mathrm{mg}$ in $47 \%$, and $40 \mathrm{mg}$ in $35 \%$ with a median of 5.8 days of use [243].

\section{Management of Respiratory Failure}

Although a comprehensive review of the optimal support of oxygenation and ventilation in COVID-19 respiratory failure is beyond the scope of this manuscript, several key physiologic insights should be recognized.

Early publications quickly highlighted the puzzling discordance between the degree of hypoxemia and modest work of breathing observed in COVID-19 patients, describing it as "silent hypoxemia" and such patients as "happy hypoxemics" [244, 245]. Similarly, soon after MV was instituted, unexpectedly high degrees of lung compliance in conjunction with severe hypoxemia was deemed a new "L" phenotype. Although reasons for lack of dyspnea are multiple, the largest contributors are: 1) early COVID-19 is an "organizing pneumonia" representing a cellular infiltration into the alveoli and ducts rather than alveolar fluid accumulation/edema as in classic ARDS making the lung "dry and light" versus "heavy and fluid-filled" and thus leads to less energy work to inflate and counter-act de-recruitment; 2) the as yet un-explained, paradoxical hyperperfusion of the foci of organizing pneumonia suggesting a failure of typical hypoxic pulmonary vasoconstriction and causing disproportionate hypoxemia (Fig. 2); and 3 ) the likely early and extensive micro- and/or macrovascular clotting not detected on routine imaging studies [8, 246, 247].

These differences from "traditional ARDS" were unfortunately both widely minimized and overlooked as evidenced by frequent recommendations for "early intubation" in what was an unfounded fear of the mechanically well-tolerated hypoxemia. Such approaches likely contributed to not only the unacceptably high mortality first reported but also the widespread shortages of ventilators, ICU beds, ventilators, nurses and medications in some of the earliest hard-hit areas. Such approaches curiously departed from the long held therapeutic principle of instituting MV, "neither too early, nor too late", with decisions to intubate resting upon an assessment of the patients' work of breathing (WOB) and their ability to sustain that work rather than solely on a presumed necessary level of oxygen saturation. When WOB is felt excessive or unsustainable despite non-invasive modes, then and only then should initiation of invasive mechanical support be pursued. Our recommended strategy for COVID-19 respiratory failure is illustrated in Figure 3. With similar approaches, many centers quickly learned that adopting such a primary focus on the support of oxygenation using non-invasive means and methods (self-proning) led to less need for ventilators and ICU beds with improved outcomes.

\section{Salvage Therapy}

It has become increasingly recognized that the pathophysiologic mechanisms leading to hospitalization in COVID-19 occur in phases (Fig. 4) largely driven by the systemic host response phase rather than the cytopathic viral replicative phase [248]. Since the host response is now understood as a complex interaction of inflammation, endotheliopathy, cytokine storm, and hypercoagulability, some have argued that TPE could offer unique benefits by removing cytokines, stabilizing endothelial membranes, and reversing the hypercoagulable state [249].

In several of the authors' clinical experiences, they have 


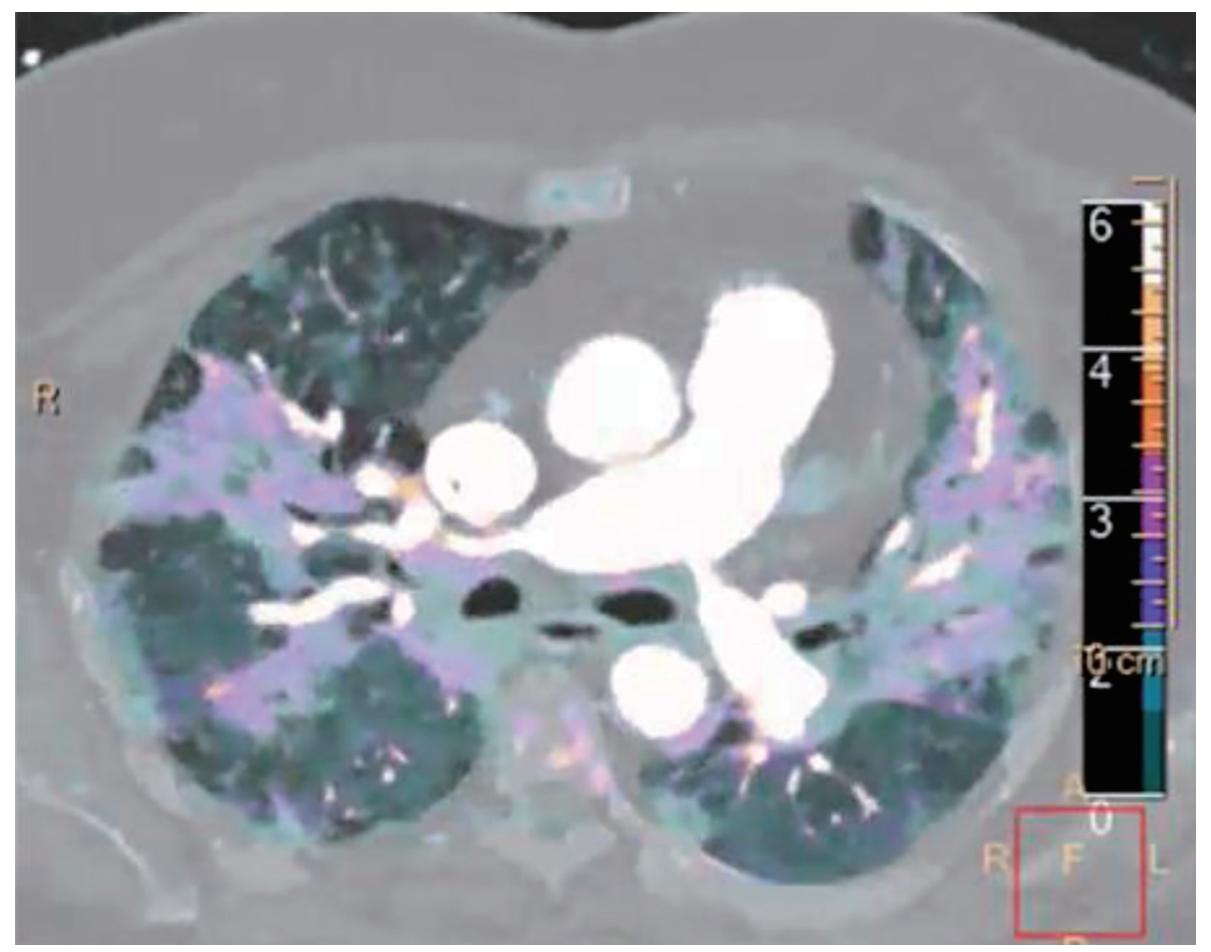

Figure 2. Spectral computed tomography (CT) image with contrast in a coronavirus disease 2019 (COVID-19) patient. Markedly increased iodine uptake is seen (color scale on right of image), indicating increased perfusion to the ground glass opacities.

General schema for respiratory support in patients with CovID-19

$$
\text { TRY TO AVOID INTUBATION IF POSSIBLE }
$$

Low flow nasal cannula

- Typically set at 1-6 liters/minute

\section{High flow nasal cannula}

- Accept permissive hypoxemia $\left(0_{2}\right.$ Saturation $\left.>86 \%\right)$

- Titrate $\mathrm{FiO}_{2}$ based on patient's saturation

- Accept flow rates of 60 to $80 \mathrm{~L} / \mathrm{min}$

- Trial of inhaled Flolan (epoprostenol)

- Attempt proning (cooperative proning)

Invasive mechanical ventilation

- Target tidal volumes of $-6 \mathrm{cc} / \mathrm{kg}$.

- Lowest driving pressure and PEEP

- Sedation to avoid self-extubation

- Trial of inhaled Flolan

\section{Prone positioning}

- Exact indication for prone ventilation is unclear.

- Consider in patients with $\mathrm{PaO}_{2} / \mathrm{FiO}_{2}$ ratio « 150 .

\section{Salvage Therapies}

- High dose corticosteroids; $120-250 \mathrm{mg}$ methylprednisolone, every 6-8 hours

- Plasma exchange

- "Half-dose" rTPA (If acute or severely increased dead space ventilation detected)

Figure 3. Therapeutic approach to hypoxemia and respiratory failure in coronavirus disease 2019 (COVID-19). 


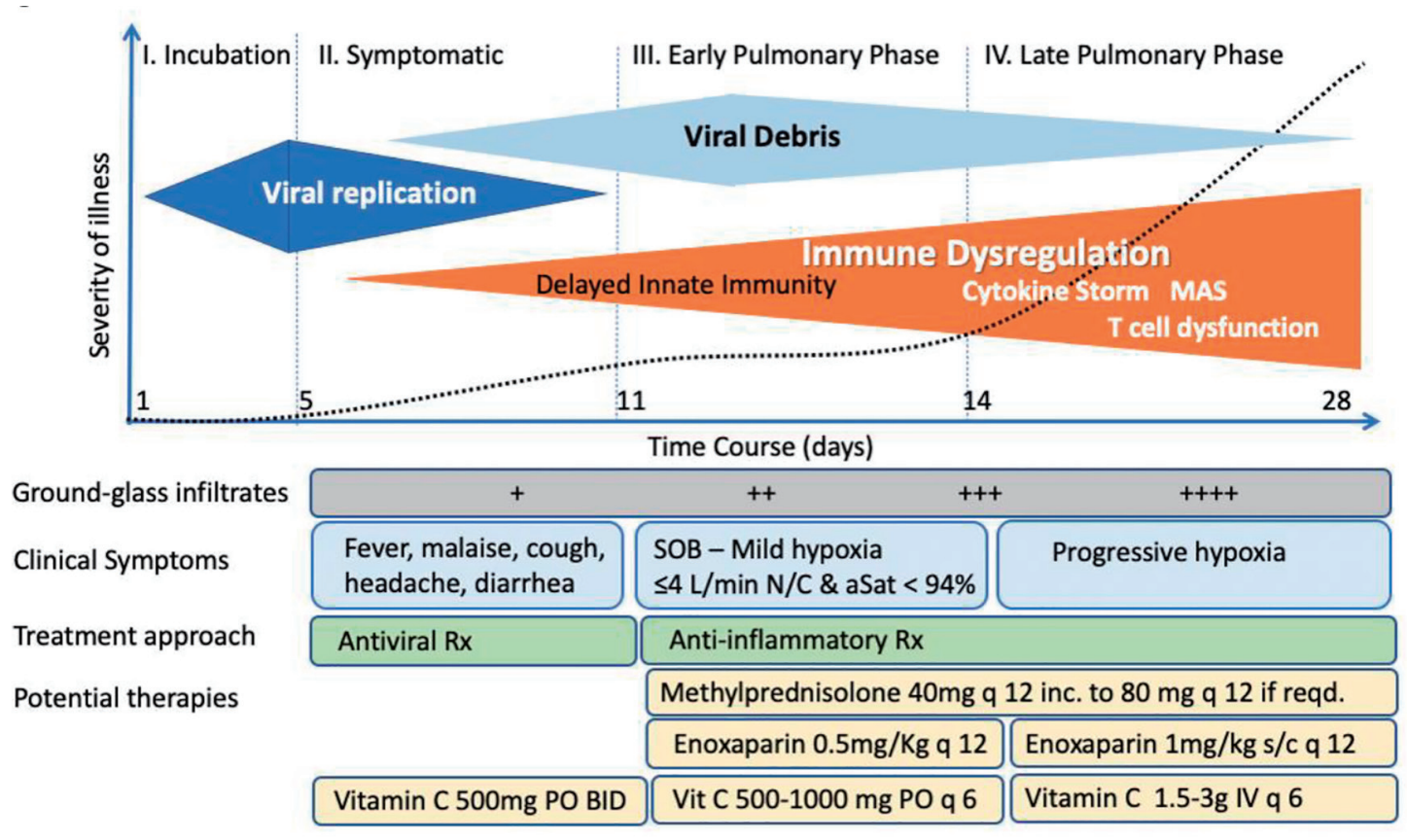

Figure 4. Phases of coronavirus disease 2019 (COVID-19).

encountered a subset of patients who have failed to respond physiologically to the combined therapies that make up the $\mathrm{MATH}+$ protocol, largely thought secondary to advanced disease at the time of presentation or extensive co-morbidity. In the first such cases, TPE was trialed with temporally associated physiologic improvements observed which then led to both extubation and discharge. In two of the authors' experiences (PEM, PK), at the time of this writing, they encountered a total of 16 patients that demonstrated little physiologic improvement despite being treated with high-dose MATH+ protocol who were then empirically treated with TPE. Thirteen of the 16 were extubated and discharged while three failed to respond and later died. Increasing publications of case series and case reports from centers across the world have now described the efficacy of TPE in over 60 COVID-19 patients that did not respond to initial therapies, with the majority having been treated with corticosteroids [250-261]. Nearly all describe similar positive physiologic and clinical responses temporally associated with initiation or completion of TPE. Further, three retrospective, observational cohort studies including a total of 74 patients treated with plasmapheresis have reported dramatic differences in both extubation and survival [262-264]. The largest, a study from Pakistan of 45 COVID-19 patients treated with plasmapheresis compared to 45 propensity-matched controls, reported that the mortality in the plasmapheresis treated group was $8.9 \%$ vs. $38.5 \%$ in controls (HR: 0.21 , 95\% CI: 0.09 - 0.53, log rank 0.002) 263]. Khamis et al in Oman published on 31 COVID-19 patients in moderate to severe respiratory failure where 11 of the more severely ill patients received TPE with a slightly higher proportion of the TPE group also receiving tocilizumab compared to controls [263]. They reported both large improvements in extubation rates (73\% vs. $20 \%, \mathrm{P}$ $=0.018)$ and mortality ( $0 \%$ vs. $35 \%, \mathrm{P}=0.03)$.
Although these studies are strongly suggestive of a role for TPE in the management of COVID-19 patients unresponsive to now standard therapies such as corticosteroids, both prospective and/or randomized studies should be done to better establish the indications, duration, and efficacy of TPE.

\section{Conclusion}

In conclusion, the varied pathophysiologic mechanisms identified in COVID-19 likely require multiple therapeutic agents working in concert to counteract the diverse, deleterious consequences of this aberrant immune response. It is exceedingly unlikely that a "magic bullet" will be found, or even a medicine which would be effective at multiple stages of the disease. The $\mathrm{MATH}+$ treatment protocol instead offers an inexpensive combination of medicines with a well-known safety profile based on strong physiologic rationale and an increasing clinical evidence base which potentially offers a life-saving approach to the management of COVID-19 patients.

\section{Acknowledgments}

Thanks for Frank Benno Junghans for the creation and design of Tables 1 and 2 and Dr. Gopal Punjabi for providing the image in Figure 2.

\section{Financial Disclosure}

None to declare. 


\section{Conflict of Interest}

The authors declare that there is no conflict of interest.

\section{Author Contributions}

Dr. Meduri's contribution is the result of work supported with the resources and use of facilities at the Memphis VA Medical Center. The contents of this commentary do not represent the views of the US Department of Veterans Affairs or the United States Government.

\section{Data Availability}

The authors declare that data supporting the findings of this study are available within the article.

\section{Author Note}

A version of this manuscript was published by The Journal of Intensive Care Medicine and was retracted by the editors after being published and highly cited. The article has been changed, the contested findings have been removed, and we have added the addition of antiandrogen therapy. It is noteworthy that this manuscript emphasizing the benefit of corticosteroid anticoagulant and antioxidant therapy in patients with COVID-19 was conceived of before the results of the recovery trial were known.

\section{References}

1. Arshad S, Kilgore P, Chaudhry ZS, Jacobsen G, Wang DD, Huitsing K, Brar I, et al. Treatment with hydroxychloroquine, azithromycin, and combination in patients hospitalized with COVID-19. Int J Infect Dis. 2020;97:396-403.

2. Docherty AB, Harrison EM, Green CA, Hardwick HE, Pius R, Norman L, Holden KA, et al. Features of 20133 UK patients in hospital with covid-19 using the ISARIC WHO Clinical Characterisation Protocol: prospective observational cohort study. BMJ. 2020;369:m1985.

3. Wilson KC, Chotirmall SH, Bai C, Rello J. COVID-19: interim guidance on management pending empirical evidence. American Thoracic Society-led International Task Force. 2020. Available from: https://www.lifebridgehealth.org/Uploads/Public/Documents/research/2020\%20 COVID\%20Articles/COVID\%20Guidelines/covid-19guidance.pdf.

4. CDC Information for Clinicians on Investigational Therapeutics for Patients with COVID-19. Public Health Media Library. 2020.

5. WHO clinical management of severe acute respiratory infection when novel coronavirus (2019-NCoV) infection is suspected. Interim Guidance. WHO. 2020.

6. Villar J, Confalonieri M, Pastores SM, Meduri GU. Ration- ale for prolonged corticosteroid treatment in the acute respiratory distress syndrome caused by coronavirus disease 2019. Crit Care Explor. 2020;2(4):e0111.

7. Kanne JP, Little BP, Chung JH, Elicker BM, Ketai LH. Essentials for Radiologists on COVID-19: An Update-Radiology Scientific Expert Panel. Radiology. 2020;296(2):E113E114.

8. Kory P, Kanne JP. SARS-CoV-2 organising pneumonia: 'Has there been a widespread failure to identify and treat this prevalent condition in COVID-19?'. BMJ Open Respir Res. 2020;7(1):e000724.

9. Richardson S, Hirsch JS, Narasimhan M, Crawford JM, McGinn T, Davidson KW, Northwell COVID-19 Research Consortium. Presenting characteristics, comorbidities, and outcomes among 5700 patients hospitalized with COVID-19 in the New York City Area. JAMA. 2020;323(20):2052-2059.

10. Zhou F, Yu T, Du R, Fan G, Liu Y, Liu Z, Xiang J, et al. Clinical course and risk factors for mortality of adult inpatients with COVID-19 in Wuhan, China: a retrospective cohort study. Lancet. 2020;395(10229):1054-1062.

11. RECOVERY Collaborative Group, Horby P, Lim WS, Emberson JR, Mafham M, Bell JL, Linsell L, et al. Dexamethasone in hospitalized patients with COVID-19 - preliminary report. N Engl J Med. 2021;384(8):693-704.

12. Nadkarni GN, Lala A, Bagiella E, Chang HL, Moreno PR, Pujadas E, Arvind V, et al. Anticoagulation, bleeding, mortality, and pathology in hospitalized patients with COVID-19. J Am Coll Cardiol. 2020;76(16):1815-1826.

13. Zhang XJ, Qin JJ, Cheng X, Shen L, Zhao YC, Yuan Y, Lei $F$, et al. In-hospital use of statins is associated with a reduced risk of mortality among individuals with COVID-19. Cell Metab. 2020;32(2):176-187.e4.

14. Entrenas Castillo M, Entrenas Costa LM, Vaquero Barrios JM, Alcala Diaz JF, Lopez Miranda J, Bouillon R, Quesada Gomez JM. "Effect of calcifediol treatment and best available therapy versus best available therapy on intensive care unit admission and mortality among patients hospitalized for COVID-19: A pilot randomized clinical study". J Steroid Biochem Mol Biol. 2020;203:105751.

15. Richmond L, Schneider RP, Steffel J, Sandor PS, Tarnutzer AA. Case report: new-onset retinal migraine after transseptal catheterization. Headache. 2020;60(2):463-468.

16. Jehi L, Ji X, Milinovich A, Erzurum S, Rubin BP, Gordon $\mathrm{S}$, Young JB, et al. Individualizing risk prediction for positive coronavirus disease 2019 testing: results from 11,672 patients. Chest. 2020;158(4):1364-1375.

17. Nicastri E, Petrosillo N, Ascoli Bartoli T, Lepore L, Mondi A, Palmieri F, D'Offizi G, et al. National Institute for the Infectious Diseases "L. Spallanzani", IRCCS. Recommendations for COVID-19 clinical management. Infect Dis Rep. 2020;12(1):8543.

18. Ye Z, Rochwerg B, Wang Y, Adhikari NK, Murthy S, Lamontagne F, Fowler RA, et al. Treatment of patients with nonsevere and severe coronavirus disease 2019: an evidence-based guideline. CMAJ. 2020;192(20):E536-E545.

19. Massachusetts General Hospital. Background: hydroxychloroquine and COVID-19. Mass General Hospital. Published April 25, 2020. Accessed April 26, 2020. https:// 
www.massgeneral.org/assets/MGH/pdf/news/coronavirus/ background-on-hydroxychloroquine-and-covid-19.PDF.

20. Yale New-Haven Hospital System. Initial treatment algorithm for hospitalized adults with severe COVID-19 respiratory failure, including mechanical ventilation and ECMO PLUS confirmed POSITIVE SARS-CoV-2 by PCR. Yale New-Haven Hospital System. Published April 1, 2020. Accessed April 10, 2020. https://medicine.yale.edu/newsarticle/23611/.

21. China National Health Commission. Chinese Clinical Guidance for Covid-19 Pneumonia (7th Edition) 2020. China National Health Commission. Published March 16, 2020. Accessed November 11, 2020. http://kjfy.meetingchina.org/msite/news/show/cn/3337.html.

22. Waterer GW, Rello J, Wunderink RG. COVID-19: first do no harm. Am J Respir Crit Care Med. 2020;201(11):13241325.

23. Villar J, Confalonieri M, Pastores SM, Meduri GU. Rationale for prolonged corticosteroid treatment in the acute respiratory distress syndrome caused by coronavirus disease 2019. Crit Care Explor. 2020;2:e0111.

24. Marik PE, Iglesias J, Varon J, Kory P. A scoping review of the pathophysiology of COVID-19. Int J Immunopathol Pharmacol. 2021;35:20587384211048026.

25. Meduri GU, Annane D, Chrousos GP, Marik PE, Sinclair SE. Activation and regulation of systemic inflammation in ARDS: rationale for prolonged glucocorticoid therapy. Chest. 2009;136(6):1631-1643.

26. Park JH, Lee HK. Re-analysis of single cell transcriptome reveals that the NR3C1-CXCL8-Neutrophil axis determines the severity of COVID-19. Front Immunol. 2020;11:2145.

27. Mehta P, McAuley DF, Brown M, Sanchez E, Tattersall RS, Manson JJ, Hlh Across Speciality Collaboration UK. COVID-19: consider cytokine storm syndromes and immunosuppression. Lancet. 2020;395(10229):1033-1034.

28. Tang L, Zhang X, Wang Y, Zeng X. Severe COVID-19 pneumonia: assessing inflammation burden with volume-rendered chest CT. Radiol Cardiothorac Imaging. 2020;2(2):e200044.

29. Xu Z, Shi L, Wang Y, Zhang J, Huang L, Zhang C, Liu S, et al. Pathological findings of COVID-19 associated with acute respiratory distress syndrome. Lancet Respir Med. 2020;8(4):420-422.

30. Chen RC, Tang XP, Tan SY, Liang BL, Wan ZY, Fang JQ, Zhong N. Treatment of severe acute respiratory syndrome with glucosteroids: the Guangzhou experience. Chest. 2006;129(6):1441-1452.

31. Yam LY, Lau AC, Lai FY, Shung E, Chan J, Wong V, Hong Kong Hospital Authority SARS Collaborative Group (HASCOG). Corticosteroid treatment of severe acute respiratory syndrome in Hong Kong. J Infect. 2007;54(1):2839.

32. Long Y, Xu Y, Wang B, Zhang L, Jia D, Xue F, Duan G, et al. Clinical Recommendations from an observational study on MERS: glucocorticoids was benefit in treating SARS patients. Int J Clin Exp Med. 2016;9(5):8865-8873.

33. Li H, Yang SG, Gu L, Zhang Y, Yan XX, Liang ZA, Zhang $\mathrm{W}$, et al. Effect of low-to-moderate-dose corticosteroids on mortality of hospitalized adolescents and adults with influenza A(H1N1)pdm09 viral pneumonia. Influenza Other Respir Viruses. 2017;11(4):345-354.

34. Wu C, Chen X, Cai Y, Xia J, Zhou X, Xu S, Huang H, et al. Risk factors associated with acute respiratory distress syndrome and death in patients with coronavirus disease 2019 pneumonia in Wuhan, China. JAMA Intern Med. 2020;180(7):934-943.

35. Fadel R, Morrison AR, Vahia A, Smith ZR, Chaudhry Z, Bhargava P, Miller J, et al. Early short-course corticosteroids in hospitalized patients with COVID-19. Clin Infect Dis. 2020;71(16):2114-2120.

36. Fernandez-Cruz A, Ruiz-Antoran B, Munoz-Gomez A, Sancho-Lopez A, Mills-Sanchez P, Centeno-Soto GA, Blanco-Alonso S, et al. A retrospective controlled cohort study of the impact of glucocorticoid treatment in SARSCoV-2 infection mortality. Antimicrob Agents Chemother. 2020;64(9):e01168-20.

37. Meduri GU, Bridges L, Shih MC, Marik PE, Siemieniuk RAC, Kocak M. Prolonged glucocorticoid treatment is associated with improved ARDS outcomes: analysis of individual patients' data from four randomized trials and trial-level meta-analysis of the updated literature. Intensive Care Med. 2016;42(5):829-840.

38. Pastores SM, Annane D, Rochwerg B, Corticosteroid Guideline Task Force of S, Esicm. Guidelines for the diagnosis and management of critical illness-related corticosteroid insufficiency (CIRCI) in critically ill patients (Part II): Society of Critical Care Medicine (SCCM) and European Society of Intensive Care Medicine (ESICM) 2017. Intensive Care Med. 2018;44(4):474-477.

39. Greos LS, Vichyanond P, Bloedow DC, Irvin CG, Larsen GL, Szefler SJ, Hill MR. Methylprednisolone achieves greater concentrations in the lung than prednisolone. A pharmacokinetic analysis. Am Rev Respir Dis. 1991;144(3 Pt 1):586-592.

40. Li SMG, Miller DD, Yates CR. Evaluation of AP-1 and NF-KB inhibitory potency for oral glucocorticoids. In proceedings of the American review of respiratory disease. PharmSci. 2003;5(S1):R6173.

41. Meduri GU, Tolley EA, Chrousos GP, Stentz F. Prolonged methylprednisolone treatment suppresses systemic inflammation in patients with unresolving acute respiratory distress syndrome: evidence for inadequate endogenous glucocorticoid secretion and inflammation-induced immune cell resistance to glucocorticoids. Am J Respir Crit Care Med. 2002;165(7):983-991.

42. Draghici S, Nguyen TM, Sonna LA, Ziraldo C, Vanciu RL, Fadel R, Morrison A, et al. COVID-19: disease pathways and gene expression changes predict methylprednisolone can improve outcome in severe cases. Bioinformatics. 2021;37(17):2691-2698.

43. Arabi YM, Mandourah Y, Al-Hameed F, Sindi AA, Almekhlafi GA, Hussein MA, Jose J, et al. Corticosteroid therapy for critically ill patients with middle east respiratory syndrome. Am J Respir Crit Care Med. 2018;197(6):757767.

44. Salton F, Confalonieri P, Meduri GU, Santus P, Harari S, Scala R, Lanini S, et al. Prolonged low-dose methylpred- 
nisolone in patients with severe COVID-19 pneumonia. Open Forum Infect Dis. 2020;7(10):ofaa421.

45. Corral-Gudino L, Bahamonde A, Arnaiz-Revillas F, Gómez-Barquero J, Abadía-Otero J, García-Ibarbia C, Mora V, et al. Methylprednisolone in adults hospitalized with COVID-19 pneumonia. Wien Klin Wochenschr. 2021;133(7):303-311.

46. Salton F, Confalonieri P, Santus P, Harari S, Scala R, Lanini $\mathrm{S}$, Vertui V, et al. Prolonged low-dose methylprednisolone in patients with severe COVID-19 pneumonia. medRxiv. 2020.

47. WHO Rapid Evidence Appraisal for COVID-19 Therapies (REACT) Working Group, Sterne JAC, Murthy S, Diaz JV, Slutsky AS, Villar J, Angus DC, et al. Association between administration of systemic corticosteroids and mortality among critically ill patients with COVID-19: a meta-analysis. JAMA. 2020;324(13):1330-1341.

48. Murthy SC, Siddalingappa K, Suresh T. Nicolau's syndrome following diclofenac administration: A report of two cases. Indian J Dermatol Venereol Leprol. 2007;73(6):429431.

49. Angus DC, Derde L, Al-Beidh F, Annane D, Arabi Y, Beane A, van Bentum-Puijk W, et al. Effect of hydrocortisone on mortality and organ support in patients with severe COVID-19: the REMAP-CAP COVID-19 corticosteroid domain randomized clinical trial. JAMA. 2020; 324(13):1317-1329.

50. Dequin PF, Heming N, Meziani F, Plantefeve G, Voiriot G, Badie J, Francois B, et al. Effect of hydrocortisone on 21day mortality or respiratory support among critically ill patients with COVID-19: a randomized clinical trial. JAMA. 2020;324(13):1298-1306.

51. Recovery Collaborative Group, Horby P, Lim WS, Emberson JR, Mafham M, Bell JL, Linsell L, et al. Dexamethasone in hospitalized patients with COVID-19. N Engl J Med. 2021;384(8):693-704.

52. Tomazini BM, Maia IS, Cavalcanti AB, Berwanger O, Rosa RG, Veiga VC, Avezum A, et al. Effect of dexamethasone on days alive and ventilator-free in patients with moderate or severe acute respiratory distress syndrome and COVID-19: the CoDEX randomized clinical trial. JAMA. 2020;324(13):1307-1316.

53. Wu C, Hou D, Du C, Cai Y, Zheng J, Xu J, Chen X, et al. Corticosteroid therapy for coronavirus disease 2019-related acute respiratory distress syndrome: a cohort study with propensity score analysis. Crit Care. 2020;24(1):643.

54. Edalatifard M, Akhtari M, Salehi M, Naderi Z, Jamshidi A, Mostafaei S, Najafizadeh SR, et al. Intravenous methylprednisolone pulse as a treatment for hospitalised severe COVID-19 patients: results from a randomised controlled clinical trial. Eur Respir J. 2020;56(6):2002808.

55. Marik PE, Khangoora V, Rivera R, Hooper MH, Catravas J. Hydrocortisone, vitamin $\mathrm{C}$, and thiamine for the treatment of severe sepsis and septic shock: a retrospective before-after study. Chest. 2017;151(6):1229-1238.

56. Tanaka H, Matsuda T, Miyagantani Y, Yukioka T, Matsuda H, Shimazaki S. Reduction of resuscitation fluid volumes in severely burned patients using ascorbic acid administration: a randomized, prospective study. Arch Surg.
2000;135(3):326-331.

57. Moskowitz A, Andersen LW, Huang DT, Berg KM, Grossestreuer AV, Marik PE, Sherwin RL, et al. Ascorbic acid, corticosteroids, and thiamine in sepsis: a review of the biologic rationale and the present state of clinical evaluation. Crit Care. 2018;22(1):283.

58. Zhang M, Jativa DF. Vitamin C supplementation in the critically ill: A systematic review and meta-analysis. SAGE Open Med. 2018;6:2050312118807615.

59. Blanco-Melo D, Nilsson-Payant BE, Liu WC, Uhl S, Hoagland D, Moller R, Jordan TX, et al. Imbalanced host response to SARS-CoV-2 drives development of COVID-19. Cell. 2020;181(5):1036-1045.e1039.

60. Qin C, Zhou L, Hu Z, Zhang S, Yang S, Tao Y, Xie C, et al. Dysregulation of immune response in patients with coronavirus 2019 (COVID-19) in Wuhan, China. Clin Infect Dis. 2020;71(15):762-768.

61. Acharya D, Liu G, Gack MU. Dysregulation of type I interferon responses in COVID-19. Nat Rev Immunol. 2020;20(7):397-398.

62. Kim Y, Kim H, Bae S, Choi J, Lim SY, Lee N, Kong JM, et al. Vitamin $\mathrm{C}$ is an essential factor on the anti-viral immune responses through the production of interferon-alpha/beta at the initial stage of influenza A virus (H3N2) infection. Immune Netw. 2013;13(2):70-74.

63. Cai Y, Li YF, Tang LP, Tsoi B, Chen M, Chen H, Chen $\mathrm{XM}$, et al. A new mechanism of vitamin $\mathrm{C}$ effects on $\mathrm{A} /$ $\mathrm{FM} / 1 / 47(\mathrm{H} 1 \mathrm{~N} 1)$ virus-induced pneumonia in restraintstressed mice. Biomed Res Int. 2015;2015:675149.

64. Shah A. Novel coronavirus-induced NLRP3 inflammasome activation: a potential drug target in the treatment of COVID-19. Front Immunol. 2020;11:1021.

65. Sang X, Wang H, Chen Y, Guo Q, Lu A, Zhu X, Meng G. Vitamin C inhibits the activation of the NLRP3 inflammasome by scavenging mitochondrial ROS. Inflammasome. 2016;2:13-19.

66. Zuo Y, Yalavarthi S, Shi H, Gockman K, Zuo M, Madison JA, Blair C, et al. Neutrophil extracellular traps in COVID-19. JCI Insight. 2020;5(11):e138999.

67. Lv D, Xu Y, Cheng H, Ke Y, Zhang X, Ying K. A novel cell-based assay for dynamically detecting neutrophil extracellular traps-induced lung epithelial injuries. Exp Cell Res. 2020;394(2):112101.

68. Xu J, Zhang X, Pelayo R, Monestier M, Ammollo CT, Semeraro F, Taylor FB, et al. Extracellular histones are major mediators of death in sepsis. Nat Med. 2009;15(11):13181321.

69. Mohammed BM, Fisher BJ, Kraskauskas D, Farkas D, Brophy DF, Fowler AA, 3rd, Natarajan R. Vitamin C: a novel regulator of neutrophil extracellular trap formation. Nutrients. 2013;5(8):3131-3151.

70. Carr AC, Shaw GM, Fowler AA, Natarajan R. Ascorbatedependent vasopressor synthesis: a rationale for vitamin $\mathrm{C}$ administration in severe sepsis and septic shock? Crit Care. 2015;19:418.

71. Chatterjee IB, Majumder AK, Nandi BK, Subramanian N. Synthesis and some major functions of vitamin $\mathrm{C}$ in animals. Ann N Y Acad Sci. 1975;258:24-47.

72. Wilson JX. Mechanism of action of vitamin $\mathrm{C}$ in sepsis: 
ascorbate modulates redox signaling in endothelium. Biofactors. 2009;35(1):5-13.

73. Okamoto K, Tanaka H, Makino Y, Makino I. Restoration of the glucocorticoid receptor function by the phosphodiester compound of vitamins $\mathrm{C}$ and E, EPC-K1 (L-ascorbic acid 2-[3,4-dihydro-2,5,7,8-tetramethyl-2-(4,8,12trimethyltridecyl)-2H-1-benzopyran-6 -yl hydrogen phosphate] potassium salt), via a redox-dependent mechanism. Biochem Pharmacol. 1998;56(1):79-86.

74. Marik PE. Vitamin C for the treatment of sepsis: The scientific rationale. Pharmacol Ther. 2018;189:63-70.

75. Tyml K. Vitamin C and microvascular dysfunction in systemic inflammation. Antioxidants (Basel). 2017;6(3):49.

76. Fowler AA, 3rd, Syed AA, Knowlson S, Sculthorpe R, Farthing D, DeWilde C, Farthing CA, et al. Phase I safety trial of intravenous ascorbic acid in patients with severe sepsis. J Transl Med. 2014;12:32.

77. Iglesias J, Vassallo AV, Patel VV, Sullivan JB, Cavanaugh J, Elbaga Y. Outcomes of metabolic resuscitation using ascorbic acid, thiamine, and glucocorticoids in the early treatment of sepsis: the ORANGES trial. Chest. 2020; 158(1):164-173.

78. Fowler AA, 3rd, Truwit JD, Hite RD, Morris PE, DeWilde C, Priday A, Fisher B, et al. Effect of vitamin C infusion on organ failure and biomarkers of inflammation and vascular injury in patients with sepsis and severe acute respiratory failure: the CITRIS-ALI randomized clinical trial. JAMA. 2019;322(13):1261-1270.

79. de Grooth HJ, Elbers PWG, Vincent JL. Vitamin C for sepsis and acute respiratory failure. JAMA. 2020;323(8):792.

80. Hemila H, Chalker E. Vitamin $\mathrm{C}$ may reduce the duration of mechanical ventilation in critically ill patients: a metaregression analysis. J Intensive Care. 2020;8:15.

81. Zhang J, Rao X, Li Y, Zhu Y, Liu F, Guo G, Luo G, et al. Pilot trial of high-dose vitamin $\mathrm{C}$ in critically ill COVID-19 patients. Ann Intensive Care. 2021;11(1):5.

82. Kumari P, Dembra S, Dembra P, Bhawna F, Gul A, Ali B, Sohail $\mathrm{H}$, et al. The role of vitamin $\mathrm{C}$ as adjuvant therapy in COVID-19. Cureus. 2020;12(11):e11779.

83. JamaliMoghadamSiahkali S, Zarezade B, Koolaji S, SeyedAlinaghi S, Zendehdel A, Tabarestani M, Sekhavati Moghadam E, et al. Safety and effectiveness of high-dose vitamin C in patients with COVID-19: a randomized openlabel clinical trial. Eur J Med Res. 2021;26(1):20.

84. Gao D, Xu M, Wang G, Lv J, Ma X, Guo Y, Zhang D, et al. The efficiency and safety of high-dose vitamin $C$ in patients with COVID-19: a retrospective cohort study. Aging (Albany NY). 2021;13(5):7020-7034.

85. Zhao B, Liu M, Liu P, Peng Y, Huang J, Li M, Wang Y, et al. High dose intravenous vitamin $\mathrm{C}$ for preventing the disease aggravation of moderate COVID-19 pneumonia. A retrospective propensity matched before-after study. Front Pharmacol. 2021;12:638556.

86. Suna K, Melahat US, Murat Y, Figen OE, Ayperi O. Effect of high-dose intravenous vitamin $\mathrm{C}$ on prognosis in patients with SARS-CoV-2 pneumonia. Med Clin (Barc). 2021.

87. Li M, Ching TH, Hipple C, Lopez R, Sahibzada A, Rahman H. Use of intravenous vitamin $\mathrm{C}$ in critically ill pa- tients with COVID-19 infection. J Pharm Pract. 2021.

88. Xia G, Fan D, He Y, Zhu Y, Zheng Q. High-dose intravenous vitamin $\mathrm{C}$ attenuates hyperinflammation in severe coronavirus disease 2019. Nutrition. 2021;91-92:111405.

89. Xia G, Qin B, Ma C, Zhu Y, Zheng Q. High-dose vitamin $\mathrm{C}$ ameliorates cardiac injury in COVID-19 pandemic: a retrospective cohort study. Aging (Albany NY). 2021; 13(17):20906-20914.

90. Glickman LB, Geigle PR, Paleg GS. A systematic review of supported standing programs. J Pediatr Rehabil Med. 2010;3(3):197-213.

91. Collie JTB, Greaves RF, Jones OAH, Lam Q, Eastwood GM, Bellomo R. Vitamin B1 in critically ill patients: needs and challenges. Clin Chem Lab Med. 2017;55(11):16521668.

92. Menezes RR, Godin AM, Rodrigues FF, Coura GME, Melo ISF, Brito AMS, Bertollo CM, et al. Thiamine and riboflavin inhibit production of cytokines and increase the anti-inflammatory activity of a corticosteroid in a chronic model of inflammation induced by complete Freund's adjuvant. Pharmacol Rep. 2017;69(5):1036-1043.

93. Donnino MW, Carney E, Cocchi MN, Barbash I, Chase M, Joyce N, Chou PP, et al. Thiamine deficiency in critically ill patients with sepsis. J Crit Care. 2010;25(4):576-581.

94. Costa NA, Gut AL, de Souza Dorna M, Pimentel JA, Cozzolino SM, Azevedo PS, Fernandes AA, et al. Serum thiamine concentration and oxidative stress as predictors of mortality in patients with septic shock. J Crit Care. 2014;29(2):249-252.

95. Corcoran TB, O'Neill MA, Webb SA, Ho KM. Prevalence of vitamin deficiencies on admission: relationship to hospital mortality in critically ill patients. Anaesth Intensive Care. 2009;37(2):254-260.

96. Donnino MW, Andersen LW, Chase M, Berg KM, Tidswell M, Giberson T, Wolfe R, et al. Randomized, doubleblind, placebo-controlled trial of thiamine as a metabolic resuscitator in septic shock: a pilot study. Crit Care Med. 2016;44(2):360-367.

97. Woolum JA, Abner EL, Kelly A, Thompson Bastin ML, Morris PE, Flannery AH. Effect of thiamine administration on lactate clearance and mortality in patients with septic shock. Crit Care Med. 2018;46(11):1747-1752.

98. Moslemi R, Khalili H, Mohammadi M, Mehrabi Z, Mohebbi N. Thiamine for prevention of postoperative delirium in patients undergoing gastrointestinal surgery: a randomized clinical trial. J Res Pharm Pract. 2020;9(1):30-35.

99. De Biasi S, Meschiari M, Gibellini L, Bellinazzi C, Borella R, Fidanza L, Gozzi L, et al. Marked T cell activation, senescence, exhaustion and skewing towards TH17 in patients with COVID-19 pneumonia. Nat Commun. 2020;11(1):3434.

100. Vatsalya V, Li F, Frimodig JC, Gala KS, Srivastava S, Kong M, Ramchandani VA, et al. Therapeutic prospects for Th17 cell immune storm syndrome and neurological symptoms in COVID-19: thiamine efficacy and safety, in-vitro evidence and pharmacokinetic profile. medRxiv. 2020.

101. Al Sulaiman K, Aljuhani O, Al Dossari M, Alshahrani A, Alharbi A, Algarni R, Al Jeraisy M, et al. Evaluation of thiamine as adjunctive therapy in COVID-19 critically ill 
patients: a two-center propensity score matched study. Crit Care. 2021;25(1):223.

102. Connors JM, Levy JH. COVID-19 and its implications for thrombosis and anticoagulation. Blood. 2020; 135(23):2033-2040.

103. Cui S, Chen S, Li X, Liu S, Wang F. Prevalence of venous thromboembolism in patients with severe novel coronavirus pneumonia. J Thromb Haemost. 2020;18(6):1421-1424.

104. Danzi GB, Loffi M, Galeazzi G, Gherbesi E. Acute pulmonary embolism and COVID-19 pneumonia: a random association? Eur Heart J. 2020;41(19):1858.

105. Panigada M, Bottino N, Tagliabue P, Grasselli G, Novembrino C, Chantarangkul V, Pesenti A, et al. Hypercoagulability of COVID-19 patients in intensive care unit: A report of thromboelastography findings and other parameters of hemostasis. J Thromb Haemost. 2020;18(7):1738-1742.

106. Mortus JR, Manek SE, Brubaker LS, Loor M, Cruz MA, Trautner BW, Rosengart TK. Thromboelastographic results and hypercoagulability syndrome in patients with coronavirus disease 2019 who are critically ill. JAMA Netw Open. 2020;3(6):e2011192.

107. Llitjos JF, Leclerc M, Chochois C, Monsallier JM, Ramakers M, Auvray M, Merouani K. High incidence of venous thromboembolic events in anticoagulated severe COVID-19 patients. J Thromb Haemost. 2020;18(7):17431746.

108. Lim W, Meade M, Lauzier F, Zarychanski R, Mehta S, Lamontagne F, Dodek P, et al. Failure of anticoagulant thromboprophylaxis: risk factors in medical-surgical critically ill patients*. Crit Care Med. 2015;43(2):401-410.

109. Middeldorp S, Coppens M, van Haaps TF, Foppen M, Vlaar AP, Muller MCA, Bouman CCS, et al. Incidence of venous thromboembolism in hospitalized patients with COVID-19. J Thromb Haemost. 2020;18(8):1995-2002.

110. Thomas W, Varley J, Johnston A, Symington E, Robinson M, Sheares K, Lavinio A, et al. Thrombotic complications of patients admitted to intensive care with COVID-19 at a teaching hospital in the United Kingdom. Thromb Res. 2020;191:76-77.

111. Cattaneo M, Bertinato EM, Birocchi S, Brizio C, Malavolta D, Manzoni M, Muscarella G, et al. Pulmonary embolism or pulmonary thrombosis in COVID-19? Is the recommendation to use high-dose heparin for thromboprophylaxis justified? Thromb Haemost. 2020;120(8):1230-1232.

112. Shi L, Xu J, Duan G, Yang H, Wang Y. The pooled prevalence of pulmonary embolism in patients with COVID-19. Intensive Care Med. 2020;46(11):2089-2091.

113. Wichmann D, Sperhake JP, Lutgehetmann M, Steurer S, Edler C, Heinemann A, Heinrich F, et al. Autopsy findings and venous thromboembolism in patients with COVID-19: a prospective cohort study. Ann Intern Med. 2020;173(4):268-277.

114. Ackermann M, Verleden SE, Kuehnel M, Haverich A, Welte T, Laenger F, Vanstapel A, et al. Pulmonary vascular endothelialitis, thrombosis, and angiogenesis in COVID-19. N Engl J Med. 2020;383(2):120-128.

115. Rapkiewicz AV, Mai X, Carsons SE, Pittaluga S, Kleiner DE, Berger JS, Thomas S, et al. Megakaryocytes and platelet-fibrin thrombi characterize multi-organ thrombosis at autopsy in COVID-19: A case series. EClinicalMedicine. 2020;24:100434.

116. Bryce C, Grimes Z, Pujadas E, Ahuja S, Beasley MB, Albrecht R, Hernandez T, et al. Pathophysiology of SARSCoV-2: the Mount Sinai COVID-19 autopsy experience. Mod Pathol. 2021;34(8):1456-1467.

117. Fridman S, Bres Bullrich M, Jimenez-Ruiz A, Costantini P, Shah P, Just C, Vela-Duarte D, et al. Stroke risk, phenotypes, and death in COVID-19: Systematic review and newly reported cases. Neurology. 2020;95(24):e3373e3385.

118. Tang N, Bai H, Chen X, Gong J, Li D, Sun Z. Anticoagulant treatment is associated with decreased mortality in severe coronavirus disease 2019 patients with coagulopathy. J Thromb Haemost. 2020;18(5):1094-1099.

119. Paranjpe I, Fuster V, Lala A, Russak AJ, Glicksberg BS, Levin MA, Charney AW, et al. Association of treatment dose anticoagulation with in-hospital survival among hospitalized patients with COVID-19. J Am Coll Cardiol. 2020;76(1):122-124.

120. Taccone FS, Gevenois PA, Peluso L, Pletchette Z, Lheureux O, Brasseur A, Garufi A, et al. Higher intensity thromboprophylaxis regimens and pulmonary embolism in critically ill coronavirus disease 2019 patients. Crit Care Med. 2020;48(11):e1087-e1090.

121. Clagett GP. Thrombosis research. Journal of Vascular Surgery. 1989;9:371-373.

122. Mandal AK, Dam P, Franco OL, Sellami H, Mandal S, Sezgin GC, Biswas K, et al. Response to "MacIntyre et al., 2020: A rapid systematic review of the efficacy of face masks and respirators against coronaviruses and other respiratory transmissible viruses for the community, healthcare workers and sick patients". Int J Nurs Stud. 2020;109:103714.

123. Jonmarker S, Hollenberg J, Dahlberg M, Stackelberg O, Litorell J, Everhov AH, Jarnbert-Pettersson H, et al. Dosing of thromboprophylaxis and mortality in critically ill COVID-19 patients. Crit Care. 2020;24(1):653.

124. Lemos ACB, do Espirito Santo DA, Salvetti MC, Gilio RN, Agra LB, Pazin-Filho A, Miranda CH. Therapeutic versus prophylactic anticoagulation for severe COVID-19: A randomized phase II clinical trial (HESACOVID). Thromb Res. 2020;196:359-366.

125. Investigators $\mathrm{R}-\mathrm{C}$, Investigators $\mathrm{AC}-\mathrm{a}$, Investigators $\mathrm{A}$, Goligher EC, Bradbury CA, McVerry BJ, Lawler PR, et al. Therapeutic anticoagulation with heparin in critically ill patients with COVID-19. N Engl J Med. 2021;385(9):777789.

126. Investigators A, Investigators AC-a, Investigators $\mathrm{R}-\mathrm{C}$, Lawler PR, Goligher EC, Berger JS, Neal MD, et al. Therapeutic anticoagulation with heparin in noncritically ill patients with COVID-19. N Engl J Med. 2021;385(9):790802.

127. Klok FA, Kruip M, van der Meer NJM, Arbous MS, Gommers D, Kant KM, Kaptein FHJ, et al. Confirmation of the high cumulative incidence of thrombotic complications in critically ill ICU patients with COVID-19: An updated analysis. Thromb Res. 2020;191:148-150.

128. Maier CL, Truong AD, Auld SC, Polly DM, Tanksley CL, Duncan A. COVID-19-associated hyperviscosity: a 
link between inflammation and thrombophilia? Lancet. 2020;395(10239):1758-1759.

129. Khamis F, Al-Zakwani I, Al Hashmi S, Al Dowaiki S, Al Bahrani M, Pandak N, Al Khalili H, et al. Therapeutic plasma exchange in adults with severe COVID-19 infection. Int J Infect Dis. 2020;99:214-218.

130. Lim SY, Jeon K, Kim HJ, Kim SM, Song J, Ha JM, Um $\mathrm{SW}$, et al. Antifactor Xa levels in critically ill Korean patients receiving enoxaparin for thromboprophylaxis: a prospective observational study. J Korean Med Sci. 2013;28(3):466-471.

131. Nagge J, Crowther M, Hirsh J. Is impaired renal function a contraindication to the use of low-molecular-weight heparin? Arch Intern Med. 2002;162(22):2605-2609.

132. White D, MacDonald S, Bull T, Hayman M, de Monteverde-Robb R, Sapsford D, Lavinio A, et al. Heparin resistance in COVID-19 patients in the intensive care unit. J Thromb Thrombolysis. 2020;50(2):287-291.

133. Tomasa-Irriguible TM, Martinez-Vega S, Mor-Marco E, Herraiz-Ruiz A, Raguer-Pardo L, Cubells-Larrosa C. Low molecular weight heparins in COVID-19 patients: beware of augmented renal clearance! Crit Care. 2020;24(1):325.

134. Colunga Biancatelli RML, Berrill M, Mohammed YH, Marik PE. Melatonin for the treatment of sepsis: the scientific rationale. J Thorac Dis. 2020;12(Suppl 1):S54-S65.

135. Liu J, Clough SJ, Hutchinson AJ, Adamah-Biassi EB, Popovska-Gorevski M, Dubocovich ML. MT1 and MT2 melatonin receptors: a therapeutic perspective. Annu Rev Pharmacol Toxicol. 2016;56:361-383.

136. Carrillo-Vico A, Reiter RJ, Lardone PJ, Herrera JL, Fernandez-Montesinos R, Guerrero JM, Pozo D. The modulatory role of melatonin on immune responsiveness. Curr Opin Investig Drugs. 2006;7(5):423-431.

137. Espino J, Pariente JA, Rodriguez AB. Oxidative stress and immunosenescence: therapeutic effects of melatonin. Oxid Med Cell Longev. 2012;2012:670294.

138. Dominguez-Rodriguez A, Abreu-Gonzalez P, et al. Melatonin, cardiovascular disease and COVID-19: a potential therapeutic strategy? Melatonin Res. 2020;3:318-321.

139. Reiter RJ, Sharma R, Ma Q, Dominquez-Rodriguez A, Marik PE, Abreu-Gonzalez P. Melatonin inhibits COVID19-induced cytokine storm by reversing aerobic glycolysis in immune cells: a mechanistic analysis. Med Drug Discov. 2020;6:100044.

140. Reiter RJ, Abreu-Gonzalez P, Marik PE, Dominguez-Rodriguez $\mathrm{A}$. Therapeutic algorithm for use of melatonin in patients with COVID-19. Front Med (Lausanne). 2020;7:226.

141. Zhou Y, Hou Y, Shen J, Huang Y, Martin W, Cheng F. Network-based drug repurposing for novel coronavirus 2019nCoV/SARS-CoV-2. Cell Discov. 2020;6:14.

142. Wurtman RJ. Age-related decreases in melatonin secretion-clinical consequences. J Clin Endocrinol Metab. 2000;85(6):2135-2136.

143. Zhang R, Wang X, Ni L, Di X, Ma B, Niu S, Liu C, et al. COVID-19: Melatonin as a potential adjuvant treatment. Life Sci. 2020;250:117583.

144. Aldhous M, Franey C, Wright J, Arendt J. Plasma concentrations of melatonin in man following oral absorption of different preparations. Br J Clin Pharmacol.
1985;19(4):517-521.

145. Alizadeh Z, Keyhanian N, Ghaderkhani S, Dashti-Khavidaki S, Shokouhi Shoormasti R, Pourpak Z. A pilot study on controlling coronavirus disease 2019 (COVID-19) inflammation using melatonin supplement. Iran J Allergy Asthma Immunol. 2021;20(4):494-499.

146. Farnoosh G, Akbariqomi M, Badri T, Bagheri M, Izadi M, Saeedi-Boroujeni A, Rezaie E, et al. Efficacy of a low dose of melatonin as an adjunctive therapy in hospitalized patients with COVID-19: a randomized, double-blind clinical trial. Arch Med Res. 2022;53(1):79-85.

147. Mousavi SA, Heydari K, Mehravaran H, Saeedi M, Alizadeh-Navaei R, Hedayatizadeh-Omran A, Shamshirian A. Melatonin effects on sleep quality and outcomes of COVID-19 patients: An open-label, randomized, controlled trial. J Med Virol. 2022;94(1):263-271.

148. Ramlall V, Zucker J, Tatonetti N. Melatonin is significantly associated with survival of intubated COVID-19 patients. medRxiv. 2020.

149. Skalny AV, Rink L, Ajsuvakova OP, Aschner M, Gritsenko VA, Alekseenko SI, Svistunov AA, et al. Zinc and respiratory tract infections: Perspectives for COVID19 (Review). Int J Mol Med. 2020;46(1):17-26.

150. Gammoh NZ, Rink L. Zinc in Infection and Inflammation. Nutrients. 2017;9(6):624.

151. Heyland DK, Jones N, Cvijanovich NZ, Wong H. Zinc supplementation in critically ill patients: a key pharmaconutrient? JPEN J Parenter Enteral Nutr. 2008;32(5):509519.

152. Lim SS, Vos T, Flaxman AD, Danaei G, Shibuya K, AdairRohani H, Amann M, et al. A comparative risk assessment of burden of disease and injury attributable to 67 risk factors and risk factor clusters in 21 regions, 1990-2010: a systematic analysis for the Global Burden of Disease Study 2010. Lancet. 2012;380(9859):2224-2260.

153. Bhutta ZA, Ahmed T, Black RE, Cousens S, Dewey K, Giugliani E, Haider BA, et al. What works? Interventions for maternal and child undernutrition and survival. Lancet. 2008;371(9610):417-440.

154. Maggini S, Wenzlaff S, Hornig D. Essential role of vitamin $\mathrm{C}$ and zinc in child immunity and health. J Int Med Res. 2010;38(2):386-414.

155. Linko R, Karlsson S, Pettila V, Varpula T, Okkonen M, Lund V, Ala-Kokko T, et al. Serum zinc in critically ill adult patients with acute respiratory failure. Acta Anaesthesiol Scand. 2011;55(5):615-621.

156. Mertens K, Lowes DA, Webster NR, Talib J, Hall L, Davies MJ, Beattie JH, et al. Low zinc and selenium concentrations in sepsis are associated with oxidative damage and inflammation. Br J Anaesth. 2015;114(6):990-999.

157. Hoeger J, Simon TP, Beeker T, Marx G, Haase H, Schuerholz T. Persistent low serum zinc is associated with recurrent sepsis in critically ill patients - A pilot study. PLoS One. 2017;12(5):e0176069.

158. Boudreault F, Pinilla-Vera M, Englert JA, Kho AT, Isabelle C, Arciniegas AJ, Barragan-Bradford D, et al. Zinc deficiency primes the lung for ventilator-induced injury. JCI Insight. 2017;2(11):e86507.

159. Singh M, Das RR. Zinc for the common cold. Cochrane 
Database Syst Rev. 2013;6:CD001364.

160. Hemila H. Zinc lozenges and the common cold: a meta-analysis comparing zinc acetate and zinc gluconate, and the role of zinc dosage. JRSM Open. 2017; 8(5):2054270417694291.

161. Meydani SN, Barnett JB, Dallal GE, Fine BC, Jacques PF, Leka LS, Hamer DH. Serum zinc and pneumonia in nursing home elderly. Am J Clin Nutr. 2007;86(4):1167-1173.

162. te Velthuis AJ, van den Worm SH, Sims AC, Baric RS, Snijder EJ, van Hemert MJ. Zn(2+) inhibits coronavirus and arterivirus RNA polymerase activity in vitro and zinc ionophores block the replication of these viruses in cell culture. PLoS Pathog. 2010;6(11):e1001176.

163. Xue J, Moyer A, Peng B, Wu J, Hannafon BN, Ding WQ. Chloroquine is a zinc ionophore. PLoS One. 2014;9(10):e109180.

164. Dabbagh-Bazarbachi H, Clergeaud G, Quesada IM, Ortiz M, O'Sullivan CK, Fernandez-Larrea JB. Zinc ionophore activity of quercetin and epigallocatechin-gallate: from Hepa 1-6 cells to a liposome model. J Agric Food Chem. 2014;62(32):8085-8093.

165. Shittu MO, Afolami OI. Improving the efficacy of Chloroquine and Hydroxychloroquine against SARS-CoV-2 may require Zinc additives - A better synergy for future COVID-19 clinical trials. Infez Med. 2020;28(2):192-197.

166. Sukhatme VP, Reiersen AM, Vayttaden SJ, Sukhatme VV. Fluvoxamine: A Review of Its Mechanism of Action and Its Role in COVID-19. Front Pharmacol. 2021;12:652688.

167. Hoertel N, Sanchez-Rico M, Vernet R, Beeker N, Jannot AS, Neuraz A, Salamanca E, et al. Association between antidepressant use and reduced risk of intubation or death in hospitalized patients with COVID-19: results from an observational study. Mol Psychiatry. 2021;26(9):5199-5212.

168. Carpinteiro A, Edwards MJ, Hoffmann M, Kochs G, Gripp $\mathrm{B}$, Weigang S, Adams C, et al. Pharmacological Inhibition of Acid Sphingomyelinase Prevents Uptake of SARS-CoV-2 by Epithelial Cells. Cell Rep Med. 2020;1(8):100142.

169. Lenze EJ, Mattar C, Zorumski CF, Stevens A, Schweiger J, Nicol GE, Miller JP, et al. Fluvoxamine vs placebo and clinical deterioration in outpatients with symptomatic COVID-19: a randomized clinical trial. JAMA. 2020;324(22):2292-2300.

170. Reis G, Dos Santos Moreira-Silva EA, Silva DCM, Thabane L, Milagres AC, Ferreira TS, Dos Santos CVQ, et al. Effect of early treatment with fluvoxamine on risk of emergency care and hospitalisation among patients with COVID-19: the TOGETHER randomised, platform clinical trial. Lancet Glob Health. 2022;10(1):e42-e51.

171. Gebhard C, Regitz-Zagrosek V, Neuhauser HK, Morgan R, Klein SL. Impact of sex and gender on COVID-19 outcomes in Europe. Biol Sex Differ. 2020;11(1):29.

172. Lee J, Yousaf A, Fang W, Kolodney MS. Male balding is a major risk factor for severe COVID-19. J Am Acad Dermatol. 2020;83(5):e353-e354.

173. Wambier CG, Vano-Galvan S, McCoy J, Gomez-Zubiaur A, Herrera S, Hermosa-Gelbard A, Moreno-Arrones OM, et al. Androgenetic alopecia present in the majority of patients hospitalized with COVID-19: The "Gabrin sign". J Am Acad Dermatol. 2020;83(2):680-682.
174. Salazar Arenas MA, Munoz Del Carpio-Toia A, Aybar Galdos J, Rodriguez-Morales AJ. Alopecia and severity of COVID-19: a cross-sectional study in Peru. Infez Med. 2021;29(1):37-45.

175. Wambier CG, McCoy J, Goren A. Male balding as a major risk factor for severe COVID-19: A possible role for targeting androgens and transmembrane protease serine 2 to protect vulnerable individuals. J Am Acad Dermatol. 2020;83(6):e401-e402.

176. Cadegiani F, Lin EM, Goren A, Wambier CG. Potential risk for developing severe COVID-19 disease among anabolic steroid users. BMJ Case Rep. 2021;14(2):e241572.

177. Velavan TP, Pallerla SR, Ruter J, Augustin Y, Kremsner PG, Krishna S, Meyer CG. Host genetic factors determining COVID-19 susceptibility and severity. EBioMedicine. 2021;72:103629.

178. McCoy J, Wambier CG, Herrera S, Vano-Galvan S, Gioia F, Comeche B, Ron R, et al. Androgen receptor genetic variant predicts COVID-19 disease severity: a prospective longitudinal study of hospitalized COVID-19 male patients. J Eur Acad Dermatol Venereol. 2021;35(1):e15-e17.

179. Subramanian A, Anand A, Adderley NJ, Okoth K, Toulis KA, Gokhale K, Sainsbury C, et al. Increased COVID-19 infections in women with polycystic ovary syndrome: a population-based study. Eur J Endocrinol. 2021; 184(5):637-645.

180. Cadegiani FA, Lim RK, Goren A, McCoy J, Situm M, Kovacevic M, Vano Galvan S, et al. Clinical symptoms of hyperandrogenic women diagnosed with COVID-19. J Eur Acad Dermatol Venereol. 2021;35(2):e101-e104.

181. Patel VG, Zhong X, Liaw B, Tremblay D, Tsao CK, Galsky MD, Oh WK. Does androgen deprivation therapy protect against severe complications from COVID-19? Ann Oncol. 2020;31(10):1419-1420.

182. Montopoli M, Zumerle S, Vettor R, Rugge M, Zorzi M, Catapano CV, Carbone GM, et al. Androgen-deprivation therapies for prostate cancer and risk of infection by SARSCoV-2: a population-based study $(\mathrm{N}=4532)$. Ann Oncol. 2020;31(8):1040-1045.

183. Bhowmick NA, Oft J, Dorff T, Pal S, Agarwal N, Figlin RA, Posadas EM, et al. COVID-19 and androgen-targeted therapy for prostate cancer patients. Endocr Relat Cancer. 2020;27(9):R281-R292.

184. Lee KM, Heberer K, Gao A, Becker DJ, Loeb S, Makarov DV, Gulanski B et al. A Population-Level Analysis of the Protective Effects of Androgen Deprivation Therapy against COVID-19 Disease Incidence and Severity. medRxiv. 2021.

185. Experton B, Tetteh HA, Lurie N, Walker P, Elena A, Hein CS, Schwendiman B, et al. A predictive model for severe COVID-19 in the medicare population: a tool for prioritizing primary and booster COVID-19 vaccination. Biology (Basel). 2021;10(11):1185.

186. Hoffmann M, Kleine-Weber H, Schroeder S, Kruger N, Herrler T, Erichsen S, Schiergens TS, et al. SARSCoV-2 cell entry depends on ACE2 and TMPRSS2 and is blocked by a clinically proven protease inhibitor. Cell. 2020;181(2):271-280.e278.

187. Afar DE, Vivanco I, Hubert RS, Kuo J, Chen E, Saffran 
DC, Raitano AB, et al. Catalytic cleavage of the androgen-regulated TMPRSS2 protease results in its secretion by prostate and prostate cancer epithelia. Cancer Res. 2001;61(4):1686-1692.

188. Wang XM, Mannan R, Xiao L. Characterization of SARSCoV-2 and host entry factors distribution in a COVID-19 autopsy series. Commun Med. 2021;1:24.

189. Kumar N, Zuo Y, Yalavarthi S, Hunker KL, Knight JS, Kanthi Y, Obi AT, et al. SARS-CoV-2 spike protein S1mediated endothelial injury and pro-inflammatory state is amplified by dihydrotestosterone and prevented by mineralocorticoid antagonism. Viruses. 2021;13(11):2209.

190. Cadegiani FA, Zimerman RA, Fonseca DN, Correia MN, Muller MP, Bet DL, Slaviero MR, et al. Final results of a randomized, placebo-controlled, two-arm, parallel clinical trial of proxalutamide for hospitalized COVID-19 patients: a multiregional, joint analysis of the Proxa-rescue AndroCoV trial. Cureus. 2021;13(12):e20691.

191. Cadegiani FA, Fonseca DN, McCoy J, Zimerman RA, Mirza FN, Correia MN, Barros RN, et al. Efficacy of proxalutamide in hospitalized COVID-19 patients: a randomized, double-blind, placebo-controlled, parallel-design clinical trial. medRxiv. 2021.

192. Cadegiani FA, Goren A, Wambier CG, Zimerman RA. Proxalutamide improves inflammatory, immunologic, and thrombogenic markers in mild-to-moderate COVID-19 males and females: an exploratory analysis of a randomized, double-blinded, placebo-controlled trial early antiandrogen therapy (EAT) with proxalutamide (The EATProxa Biochemical AndroCoV-Trial). 2021.

193. Cadegiani FA, McCoy J, Gustavo Wambier C, Goren A. Early antiandrogen therapy with dutasteride reduces viral shedding, inflammatory responses, and time-to-remission in males with COVID-19: a randomized, double-blind, placebo-controlled interventional trial (EAT-DUTA AndroCoV Trial - Biochemical). Cureus. 2021;13(2):e13047.

194. Cadegiani FA, Zimerman RA, Fonseca DN, Correia MC, McCoy J, Wambier CG, Goren A. Proxalutamide (GT0918) reduces the rate of hospitalization in mild-to-moderate COVID-19 female patients: a randomized double-blinded placebo-controlled two-arm parallel trial. medRxiv. 2021.

195. McCoy J, Goren A, Cadegiani FA, Vano-Galvan S, Kovacevic M, Situm M, Shapiro J, et al. Proxalutamide reduces the rate of hospitalization for COVID-19 male outpatients: a randomized double-blinded placebo-controlled trial. Front Med (Lausanne). 2021;8:668698.

196. Zarehoseinzade E, Allami A, Ahmadi M, Bijani B, Mohammadi N. Finasteride in hospitalized adult males with COVID-19: A risk factor for severity of the disease or an adjunct treatment: A randomized controlled clinical trial. Med J Islam Repub Iran. 2021;35:30.

197. Cadegiani FA, Zimerman RA, A G. Proxalutamide treatment for hospitalized COVID-19 patients in southern brazil: the south arm of a randomized, double-blind, placebocontrolled, parallel clinical trial - the South Proxa-Rescue AndroCoV Trial. medRxiv. 2021.

198. Zimerman RA, Fonseca DN, Correia MN, Barros RN, Onety DC, Israel KCP, Almeida BG, et al. Proxalutamide reduction of mortality rate in hospitalized COVID-19 pa- tients depends on treatment duration - an exploratory analysis of the Proxa-Rescue AndroCoV Trial. medRxiv. 2021.

199. Rondanelli M, Miccono A, Lamburghini S, Avanzato I, Riva A, Allegrini P, Faliva MA, et al. Self-care for common colds: the pivotal role of vitamin D, Vitamin C, Zinc, and echinacea in three main immune interactive clusters (Physical Barriers, Innate and Adaptive Immunity) involved during an episode of common colds-practical advice on dosages and on the time to take these nutrients/ botanicals in order to prevent or treat common colds. Evid Based Complement Alternat Med. 2018;2018:5813095.

200. Huang C, Wang Y, Li X, Ren L, Zhao J, Hu Y, Zhang L, et al. Clinical features of patients infected with 2019 novel coronavirus in Wuhan, China. Lancet. 2020;395(10223):497506.

201. Sharifi A, Vahedi H, Nedjat S, Rafiei H, Hosseinzadeh-Attar MJ. Effect of single-dose injection of vitamin D on immune cytokines in ulcerative colitis patients: a randomized placebo-controlled trial. APMIS. 2019;127(10):681-687.

202. Rossi GA, Fanous H, Colin AA. Viral strategies predisposing to respiratory bacterial superinfections. Pediatr Pulmonol. 2020;55(4):1061-1073.

203. Grant WB, Lahore H, McDonnell SL, Baggerly CA, French $\mathrm{CB}$, Aliano JL, Bhattoa HP. Evidence that vitamin D supplementation could reduce risk of influenza and COVID-19 infections and deaths. Nutrients. 2020;12(4):988.

204. Quraishi SA, Bittner EA, Blum L, Hutter MM, Camargo CA, Jr. Association between preoperative 25-hydroxyvitamin D level and hospital-acquired infections following Roux-en-Y gastric bypass surgery. JAMA Surg. 2014;149(2):112-118.

205. Cannell JJ, Vieth R, Umhau JC, Holick MF, Grant WB, Madronich S, Garland CF, et al. Epidemic influenza and vitamin D. Epidemiol Infect. 2006;134(6):1129-1140.

206. Youssef DA, Ranasinghe T, Grant WB, Peiris AN. Vitamin D's potential to reduce the risk of hospital-acquired infections. Dermatoendocrinol. 2012;4(2):167-175.

207. ONS Coronavirus (COVID-19) related deaths by Ethnic Group, England and Wales - Office for National Statistics. 2020;1-10.

208. Martineau AR, Jolliffe DA, Hooper RL, Greenberg L, Aloia JF, Bergman P, Dubnov-Raz G, et al. Vitamin D supplementation to prevent acute respiratory tract infections: systematic review and meta-analysis of individual participant data. BMJ. 2017;356:16583.

209. Maghbooli Z, Sahraian MA, Ebrahimi M, Pazoki M, Kafan S, Tabriz HM, Hadadi A, et al. Vitamin D sufficiency, a serum 25-hydroxyvitamin D at least $30 \mathrm{ng} / \mathrm{mL}$ reduced risk for adverse clinical outcomes in patients with COVID-19 infection. PLoS One. 2020;15(9):e0239799.

210. Venkatesh B, Nair P. Hypovitaminosis D and morbidity in critical illness: is there proof beyond reasonable doubt? Critical Care. 2014;18:7-9.

211. Lee P, Eisman JA, Center JR. Vitamin D deficiency in critically ill patients. N Engl J Med. 2009;360(18):1912-1914.

212. Zhang YP, Wan YD, Sun TW, Kan QC, Wang LX. Association between vitamin $\mathrm{D}$ deficiency and mortality in critically ill adult patients: a meta-analysis of cohort studies. Crit Care. 2014;18(6):684. 
213. Amrein K, Zajic P, Schnedl C, Waltensdorfer A, Fruhwald S, Holl A, Purkart T, et al. Vitamin D status and its association with season, hospital and sepsis mortality in critical illness. Crit Care. 2014;18(2):R47.

214. Putzu A, Belletti A, Cassina T, Clivio S, Monti G, Zangrillo A, Landoni G. Vitamin D and outcomes in adult critically ill patients. A systematic review and meta-analysis of randomized trials. J Crit Care. 2017;38:109-114.

215. Amrein K, Martucci G, McNally JD. When not to use meta-analysis: Analysing the meta-analyses on vitamin D in critical care. Clin Nutr. 2017;36(6):1729-1730.

216. National Heart Lung Blood Institute Petal Clinical Trials Network, Ginde AA, Brower RG, Caterino JM, Finck L, Banner-Goodspeed VM, et al. Early high-dose vitamin D3 for critically ill, vitamin D-deficient patients. N Engl J Med. 2019;381(26):2529-2540.

217. Barabutis N, Khangoora V, Marik PE, Catravas JD. Hydrocortisone and ascorbic acid synergistically prevent and repair lipopolysaccharide-induced pulmonary endothelial barrier dysfunction. Chest. 2017;152(5):954-962.

218. Journal S, Kuhbandner K, Hammer A, Haase S, Terbrack E, Schippers A, Wagner N, et al. Oral Presentations. 2018;24(S2):24.

219. Zhang Y, Leung DYM, Goleva E. Vitamin D enhances glucocorticoid action in human monocytes: involvement of granulocyte-macrophage colony-stimulating factor and mediator complex subunit 14. J Biol Chem. 2013;288(20): 14544-14553.

220. Zhang Y, Leung DY, Goleva E. Anti-inflammatory and corticosteroid-enhancing actions of vitamin $\mathrm{D}$ in monocytes of patients with steroid-resistant and those with steroid-sensitive asthma. J Allergy Clin Immunol. 2014;133(6):17441752.e1741.

221. Christopher KB. Vitamin D supplementation in the ICU patient. Curr Opin Clin Nutr Metab Care. 2015;18(2):187192.

222. Bergman P. The link between vitamin D and COVID-19: distinguishing facts from fiction. J Intern Med. 2021; 289(1):131-133.

223. Han JE, Jones JL, Tangpricha V, Brown MA, Brown LAS, Hao L, Hebbar G, et al. High dose vitamin D administration in ventilated intensive care unit patients: a pilot double blind randomized controlled trial. J Clin Transl Endocrinol. 2016;4:59-65.

224. Amrein K, Schnedl C, Berghold A, Pieber TR, Dobnig H. Correction of vitamin D deficiency in critically ill patients VITdAL@ICU study protocol of a double-blind, placebocontrolled randomized clinical trial.BMC Endocr Disord. 2012;12:27.

225. Rastogi A, Bhansali A, Khare N, Suri V, Yaddanapudi N, Sachdeva N, Puri GD, et al. Short term, high-dose vitamin D supplementation for COVID-19 disease: a randomised, placebo-controlled, study (SHADE study). Postgrad Med J. 2022;98(1156):87-90.

226. Lakkireddy M, Gadiga SG, Malathi RD, Karra ML, Raju I, Ragini, Chinapaka S, et al. Impact of daily high dose oral vitamin D therapy on the inflammatory markers in patients with COVID 19 disease. Sci Rep. 2021;11(1):10641.

227. Murai IH, Fernandes AL, Sales LP, Pinto AJ, Goessler KF,
Duran CSC, Silva CBR, et al. Effect of a single high dose of vitamin D3 on hospital length of stay in patients with moderate to severe COVID-19: a randomized clinical trial. JAMA. 2021;325(11):1053-1060.

228. Wan YD, Sun TW, Kan QC, Guan FX, Zhang SG. Effect of statin therapy on mortality from infection and sepsis: a meta-analysis of randomized and observational studies. Crit Care. 2014;18(2):R71.

229. Pertzov B, Eliakim-Raz N, Atamna H, Trestioreanu AZ, Yahav D, Leibovici L. Hydroxymethylglutaryl-CoA reductase inhibitors (statins) for the treatment of sepsis in adults - A systematic review and meta-analysis. Clin Microbiol Infect. 2019;25(3):280-289.

230. Gao XQ, Li YF, Jiang ZL. Impact of statins on ALI/ARDS: A meta-analysis. Pulm Pharmacol Ther. 2016;39:85-91.

231. Kruger P, Bailey M, Bellomo R, Cooper DJ, Harward M, Higgins A, Howe B, et al. A multicenter randomized trial of atorvastatin therapy in intensive care patients with severe sepsis. Am J Respir Crit Care Med. 2013;187(7):743750 .

232. Kruger PS, Terblanche M. Statins in patients with sepsis and ARDS: is it over? No. Intensive Care Med. 2017;43(5): 675-676.

233. McAuley DF, Laffey JG, O'Kane CM, Perkins GD, Mullan B, Trinder TJ, Johnston P, et al. Simvastatin in the acute respiratory distress syndrome. New England Journal of Medicine. 2014;371:1695-1703.

234. Calfee CS, Delucchi KL, Sinha P, Matthay MA, Hackett J, Shankar-Hari M, McDowell C, et al. Acute respiratory distress syndrome subphenotypes and differential response to simvastatin: secondary analysis of a randomised controlled trial. Lancet Respir Med. 2018;6(9):691-698.

235. Rodriguez-Nava G, Trelles-Garcia DP, Yanez-Bello MA, Chung CW, Trelles-Garcia VP, Friedman HJ. Atorvastatin associated with decreased hazard for death in COVID-19 patients admitted to an ICU: a retrospective cohort study. Crit Care. 2020;24(1):429.

236. Jafarzadeh A, Nemati M, Khorramdelazad H, Hassan ZM. Immunomodulatory properties of cimetidine: Its therapeutic potentials for treatment of immune-related diseases. Int Immunopharmacol. 2019;70:156-166.

237. Smolinska S, Groeger D, Perez NR, Schiavi E, Ferstl R, Frei R, Konieczna P, et al. Histamine receptor 2 is required to suppress innate immune responses to bacterial ligands in patients with inflammatory bowel disease. Inflamm Bowel Dis. 2016;22(7):1575-1586.

238. Morichika T, Takahashi HK, Iwagaki H, Yoshino T, Tamura R, Yokoyama M, Mori S, et al. Histamine inhibits lipopolysaccharide-induced tumor necrosis factor-alpha production in an intercellular adhesion molecule-1- and B7.1-dependent manner. J Pharmacol Exp Ther. 2003;304(2):624-633.

239. Bourinbaiar AS, Fruhstorfer EC. The effect of histamine type 2 receptor antagonists on human immunodeficiency virus (HIV) replication: identification of a new class of antiviral agents. Life Sci. 1996;59(23):PL365-PL370.

240. Goldstein JA. Cimetidine, ranitidine, and Epstein-Barr virus infection. Ann Intern Med. 1986;105(1):139.

241. Gooptu C, Higgins CR, James MP. Treatment of viral warts with cimetidine: an open-label study. Clin Exp Dermatol. 
2000;25(3):183-185.

242. Yang N, Tanner JA, Zheng BJ, Watt RM, He ML, Lu LY, Jiang JQ, et al. Bismuth complexes inhibit the SARS coronavirus. Angew Chem Int Ed Engl. 2007;46(34):64646468.

243. Freedberg DE, Conigliaro J, Wang TC, Tracey KJ, Callahan MV, Abrams JA, Sobieszczyk ME, et al. Famotidine use is associated with improved clinical outcomes in hospitalized COVID-19 patients: a propensity score matched retrospective cohort study. Gastroenterology. 2020;159(3):11291131.e3.

244. Tobin MJ, Laghi F, Jubran A. Why COVID-19 Silent Hypoxemia Is Baffling to Physicians. Am J Respir Crit Care Med. 2020;202(3):356-360.

245. Couzin-Frankel J. The Mystery of the Pandemic's "Happy Hypoxia". Science. 2020;368:455-456.

246. Cobes N, Guernou M, Lussato D, Queneau M, Songy B, Bonardel G, Grellier JF. Ventilation/perfusion SPECT/ CT findings in different lung lesions associated with COVID-19: a case series. Eur J Nucl Med Mol Imaging. 2020;47(10):2453-2460.

247. Patel BV, Arachchillage DJ, Ridge CA, Bianchi P, Doyle JF, Garfield B, Ledot S, et al. Pulmonary angiopathy in severe COVID-19: physiologic, imaging, and hematologic observations. Am J Respir Crit Care Med. 2020;202(5):690699.

248. Marik PE, Varon J, Kory P. Treatment of COVID-19 is critically phase specific. Crit Care Shock. 2020;23(5):10-12.

249. Keith P, Day M, Perkins L, Moyer L, Hewitt K, Wells A. A novel treatment approach to the novel coronavirus: an argument for the use of therapeutic plasma exchange for fulminant COVID-19. Crit Care. 2020;24(1):128.

250. Fernandez J, Gratacos-Gines J, Olivas P, Costa M, Nieto S, Mateo D, Sanchez MB, et al. Plasma exchange: an effective rescue therapy in critically ill patients with coronavirus disease 2019 infection. Crit Care Med. 2020;48(12):e1350e1355.

251. Adeli SH, Asghari A, Tabarraii R, Shajari R, Afshari S, Kalhor N, Vafaeimanesh J. Therapeutic plasma exchange as a rescue therapy in patients with coronavirus disease 2019: a case series. Pol Arch Intern Med. 2020;130(5):455458.

252. Ramanathan K, Antognini D, Combes A, Paden M, Zakhary B, Ogino M, Maclaren G, et al. Planning and provision of ECMO services for severe ARDS during the COVID-19 pandemic and other outbreaks of emerging infectious diseases. Lancet Respir Med. 2020;8(5):518-526.
253. Altmayer V, Saheb S, Rohaut B, Marois C, Cao A, Gallo A, Le Guennec L, et al. Therapeutic plasma exchange in a critically ill Covid-19 patient. J Clin Apher. 2021;36(1):179182.

254. Akkoyunlu Y, Cetin G, Bolukcu S, Okay G, Ogun H, Durdu B, Okyaltirik F, et al. The successful management of an elderly Covid-19 infected patient by plasmapheresis. Transfus Apher Sci. 2020;59(6):102924.

255. Faqihi F, Alharthy A, Alodat M, Kutsogiannis DJ, Brindley PG, Karakitsos D. Therapeutic plasma exchange in adult critically ill patients with life-threatening SARS-CoV-2 disease: A pilot study. J Crit Care. 2020;60:328-333.

256. Tian H, Sui Y, Tian S, Zou X, Xu Z, He H, Wu T. Case report: clinical treatment of the first critical patient with coronavirus disease (COVID-19) in Liaocheng, Shandong Province. Front Med (Lausanne). 2020;7:249.

257. Morath C, Weigand MA, Zeier M, Speer C, Tiwari-Heckler S, Merle U. Plasma exchange in critically ill COVID-19 patients. Crit Care. 2020;24(1):481.

258. Zhang L, Zhai H, Ma S, Chen J, Gao Y. Efficacy of therapeutic plasma exchange in severe COVID-19 patients. Br J Haematol. 2020;190(4):e181-e183.

259. Shi H, Zhou C, He P, Huang S, Duan Y, Wang X, Lin K, et al. Successful treatment with plasma exchange followed by intravenous immunoglobulin in a critically ill patient with COVID-19. Int J Antimicrob Agents. 2020;56(2):105974.

260. DePace NL, Soloway S, Roshal D, Soloway AM, Colombo J. Unexpected SARS-CoV-2 cardiorespiratory arrest in a myopathy patient undergoing immunosuppressive treatment: A case report. Medicine (Baltimore). 2020; 99(30): 21377.

261. Keith P, Day M, Choe C, Perkins L, Moyer L, Hays E, French M, et al. The successful use of therapeutic plasma exchange for severe COVID-19 acute respiratory distress syndrome with multiple organ failure. SAGE Open Med Case Rep. 2020;8:2050313X20933473.

262. Gucyetmez B, Atalan HK, Sertdemir I, Cakir U, Telci L, COVID-19 Study Group. Therapeutic plasma exchange in patients with COVID-19 pneumonia in intensive care unit: a retrospective study. Crit Care. 2020;24(1):492.

263. Ren JL, Zhang AH, Wang XJ. Corrigendum to "Traditional Chinese medicine for COVID-19 treatment" [Pharmacol. Res. 155 (2020) 104743]. Pharmacol Res. 2020; 155:104768.

264. Ren JL, Zhang AH, Wang XJ. Traditional Chinese medicine for COVID-19 treatment. Pharmacol Res. 2020; 155:104743. 